\title{
A pressurized high-flux solar reactor for the efficient thermochemical gasification of carbonaceous feedstock
}

\author{
F. Müller ${ }^{1,2}$, P. Poživil ${ }^{1}$, P.J. van Eyk ${ }^{3}$, A. Villarrazo ${ }^{4}$, P. Haueter ${ }^{1}$, C. Wieckert ${ }^{2}$, G.J. \\ Nathan ${ }^{5}$, A. Steinfeld ${ }^{1, *}$
}

Keywords: gasification, solar, concentrated, radiation, thermochemical, syngas

\begin{abstract}
We report on the design and first-ever experimental demonstration of a $3 \mathrm{~kW}$ pressurized solar reactor for thermochemically converting carbonaceous feedstocks into gaseous fuels. It uses a windowless $\mathrm{SiC}$ cavity to efficiently absorb and transfer concentrated solar radiation to an annular gas-particle vortex flow created by injecting tangentially a charcoal/water slurry at high pressures. Experiments were carried out in a high-flux solar simulator under a solar concentration ratio equivalent to 3718 suns. For slurry feeding rates in the range $0.42-1.26$ $\mathrm{g} / \mathrm{min}, \mathrm{H}_{2} \mathrm{O}: \mathrm{C}$ molar ratios in the range $1.48-1.98$, and absolute reactor pressures in the range $1-6$ bar, the nominal reactor temperature was between 1009 and $1273{ }^{\circ} \mathrm{C}$ yielding high-quality syngas with a carbon conversion up to $94 \%$ within residence times of less than 5
\end{abstract}


seconds. The peak solar-to-fuel energy conversion efficiency, defined as the ratio of the heating value of the syngas produced to the solar radiative energy input plus the heating value of the slurry converted, reached $20 \%$. The calorific value of the feedstock was solar upgraded by $35 \%$, thus outperforming autothermal gasification in addition to delivering higher syngas output per unit of feedstock and eliminating the need for upstream air separation. The performance of this robust windowless design also was compared with that of an equivalent windowed configuration in which the gas-particle vortex flow was directly exposed to highflux solar irradiation.

\section{Introduction}

Solar gasification thermochemically converts carbonaceous feedstocks into energy-rich and high-quality syngas - a mixture of $\mathrm{CO}$ and $\mathrm{H}_{2}-$ using concentrated solar energy [1]. The thermochemical conversion involves principally two sequential processes: pyrolysis and steam-based char gasification, both of which are critical in the handling of carbonaceous fuels over a wide temperature range, with the former occurring typically in the range $200-600{ }^{\circ} \mathrm{C}$ and the latter becoming dominant at above $1000{ }^{\circ} \mathrm{C}$. The simplified net reaction for stoichiometric water delivery can be represented by:

$$
C_{1} H_{x} O_{y}+(1-y) H_{2} O=\left[\frac{x}{2}+1-y\right] H_{2}+C O
$$

where $x$ and $y$ are the elemental molar ratios of $\mathrm{H}: \mathrm{C}$ and O:C in the feedstock, respectively. Nitrogen, sulfur, mineral matter, and other impurities contained in the feedstock are omitted from consideration in Eq. (1). Both pyrolysis and gasification are highly endothermic. The advantages of the solar-driven process vis-à-vis the conventional autothermal process are four-fold: 1) it delivers higher syngas output per unit of feedstock, as no portion of the feedstock is combusted for process heat; 2) it produces syngas with higher calorific value and lower $\mathrm{CO}_{2}$ intensity, as the energy content of the feedstock is upgraded through the solar 
energy input; 3) it allows for higher gasification temperatures $\left(>1200{ }^{\circ} \mathrm{C}\right)$, resulting in faster reaction kinetics and superior quality of the syngas produced with low - or without - tar content, resulting in better exploitation of the available resources; and 4) it eliminates the need for upstream air separation for oxy-combustion. Ultimately, solar gasification offers an efficient means of storing intermittent solar energy in a transportable and dispatchable chemical form. To overcome the intermittency of solar radiation, hybrid solar gasification concepts are proposed for around-the-clock process operation [2-5].

The measure of how well the solar energy input is converted into chemical energy contained in the syngas produced is given by the solar-to-fuel energy conversion efficiency $\eta_{\text {solar-to-fuel, }}$ defined as:

$$
\eta_{\text {solar-to-fuel }}=\frac{\dot{m}_{\text {syngas }} \cdot L H V_{\text {syngas }}}{\dot{Q}_{\text {solar }}+\dot{m}_{\text {feedstock }} \cdot L H V_{\text {feedstock }}}
$$

where $\dot{Q}_{\text {solar }}$ is the solar energy delivered through the solar reactor's aperture, $\dot{m}_{\text {feedstock }}$ and $\dot{m}_{\text {syngas }}$ are the gasified feedstock and the evolved syngas mass rates, respectively, and $L H V$ is the low heating value of the feedstock converted. Another important performance indicator is the energetic upgrade factor $U$, defined as the ratio of the heating value of the syngas produced to that of the feedstock processed:

$$
U=\frac{\dot{m}_{\text {syngas }} \cdot L H V_{\text {syngas }}}{\dot{m}_{\text {feedstock }} \cdot L H V_{\text {feedstock }}}
$$

For the stoichiometric system $\mathrm{C}+\mathrm{H}_{2} \mathrm{O}$, the equilibrium composition at $1300 \mathrm{~K}$ consists of an equimolar mixture of $\mathrm{H}_{2}$ and $\mathrm{CO}$, yielding $U=1.33$ for solar gasification [6]. Obviously, for autothermal gasification, $U<1$, and typically $U=0.75-0.85$ depending on the feedstock $[7,8]$.

Solar gasification reactors may be classified [1] into: 1) directly-irradiated reactors, where the solid carbonaceous reactants are directly exposed to concentrated solar irradiation; and 2) 
indirectly-irradiated reactors, where heat is transferred to the reaction site through an opaque wall. While directly-irradiated gasification reactors provide efficient heat transfer directly to the reaction site, they require a transparent window for the access of concentrated solar radiation, which becomes a critical and troublesome component at large scales and, particularly, under industrially-preferred high pressures. On the other hand, indirectlyirradiated reactors eliminate the need for a window at the expense of having less efficient heat transfer by conduction through the walls of an opaque absorber. Thus, the disadvantages are linked to the limitations imposed by the materials of the absorber with regard to maximum operating temperature, inertness to the chemical reaction, thermal conductivity, radiative absorptance, and resistance to thermal shocks. Previous experimental studies have used solar reactor concepts based on packed-beds [9-12], fluidized-beds [13-17], drop-tubes [18,19], and entrained flows $[20,21]$. Of particular interest is the directly-irradiated vortex flow reactor [20], which was successfully applied for the solar conversion of petcoke particles. However, its window became critical component during scale-up and pressurized operation because of the structural and thermal stresses [22]. This prompted us to consider converting the directlyirradiated configuration to an indirectly-irradiated one by replacing the window with a $\mathrm{SiC}$ cavity, since this configuration was recently applied successfully for heating pressurized air to $1200{ }^{\circ} \mathrm{C}$ at 6 bar using a $250 \mathrm{~mm}$-inner diameter $\mathrm{SiC}$ cavity for a solar radiative power input of $50 \mathrm{~kW}$ [23].

The present paper describes the engineering design and experimental demonstration of a $3 \mathrm{~kW}$ indirectly-irradiated (windowless) vortex flow solar reactor for the thermochemical gasification of carbonaceous particles at high pressures. To our knowledge, this is the firstever experimental demonstration of a pressurized solar gasifier. Its performance, in terms of the syngas quality, carbon conversion, upgrade factor, and solar-to-fuel energy conversion efficiency, is evaluated in the pressure range $1-6$ bars, and compared to that of a directlyirradiated (windowed) vortex flow reactor. 


\section{Experimental}

Solar Reactors - Two solar reactor configurations, shown schematically in Figure 1, were investigated: 1) the indirectly-irradiated (windowless) reactor, denoted I-I (Figure 1a); and 2) the directly-irradiated (windowed) reactor, denoted D-I (Figure 1b). Both the I-I and D-I solar reactors feature a gas-particle vortex flow following a helical path. Table 1 lists their key dimensions and materials. The I-I solar reactor consists of a flanged cylindrical SiC cavity, 30 mm-aperture, $95 \mathrm{~mm}$-inner length, $40 \mathrm{~mm}$-inner diameter, $5 \mathrm{~mm}$-thick, with a hemispherical dome. This cavity serves as the solar absorber with an apparent absorptivity of $98.8 \%$ determined by Monte Carlo ray tracing. Graphite gaskets seal the flanges. A coaxial steel/Inconel 601 shell, lined with a $\mathrm{SiO}_{2}-\mathrm{Al}_{2} \mathrm{O}_{3}$, creates an annular gap for the vortex flow. Concentrated solar radiation is absorbed by the $\mathrm{SiC}$ cavity, conducted through its walls, and transferred to the gas-particle vortex flow by combined conduction, convection, and radiation. To generate the vortex flow, $\mathrm{Ar}$ or $\mathrm{CO}_{2}$ at a flow rate of up to $15 \mathrm{~L}_{\mathrm{N}} / \mathrm{min}^{\dagger}$ was injected tangentially and directed toward the slurry feeding nozzle, as depicted in Figure 1a. The design of the D-I solar reactor was previously described in detail [20]; only the main features are highlighted here. The gas-particle vortex flow is confined to a $200 \mathrm{~mm}$-length $100 \mathrm{~mm}$ diameter cylindrical cavity-receiver, made of Inconel 601, and directly exposed to high-flux irradiation entering through a $50 \mathrm{~mm}$-diameter aperture sealed with a $3 \mathrm{~mm}$-thick transparent quartz disk. Two Ar flows were injected: one via a tangential nozzle directly behind the window at a rate of $2 \mathrm{~L}_{\mathrm{N}} / \mathrm{min}$ to cool the window and protect it from particle deposition, and a second via four tangential nozzles behind the aperture at a rate of $3 \mathrm{~L}_{\mathrm{N}} / \mathrm{min}$ to support the vortex flow.

\footnotetext{
${ }^{\dagger} \mathrm{L}_{\mathrm{N}}$ denotes normal liters; mass flow rates calculated at $273.15 \mathrm{~K}$ and $1 \mathrm{~atm}$.
} 

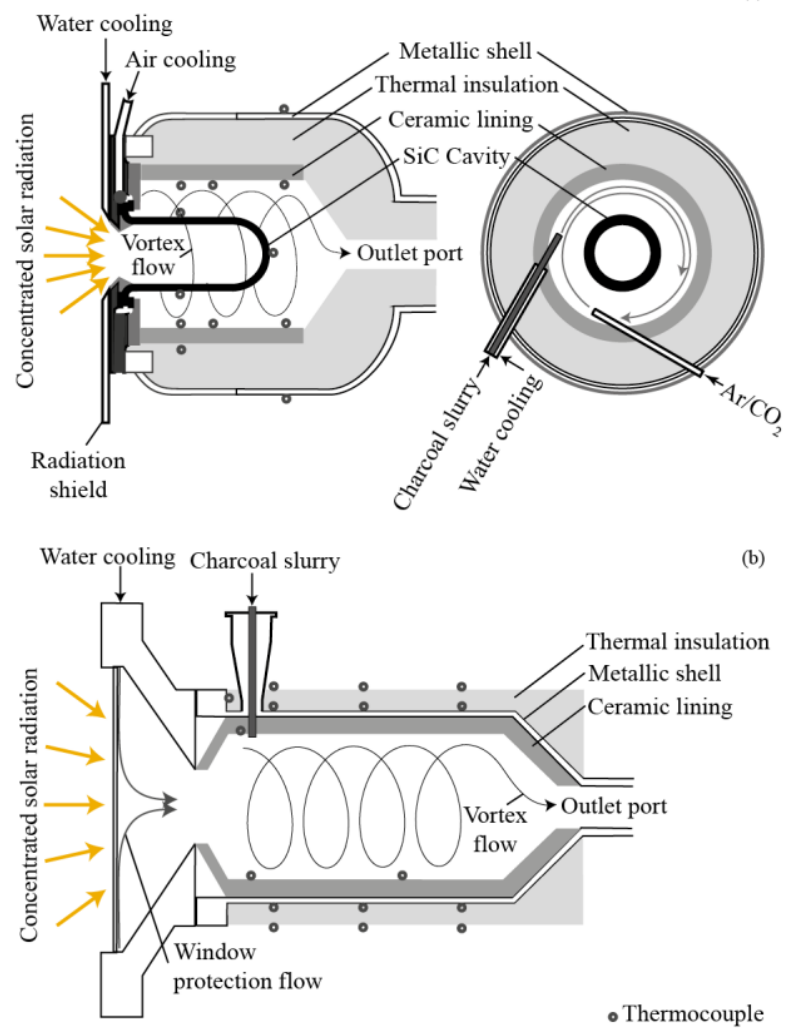

Figure 1 - Schematic of: a) the indirectly-irradiated (I-I) solar reactor; and b) the directlyirradiated (D-I) solar reactor.

Table 1 - Key dimensions and materials of the I-I and the D-I solar reactors

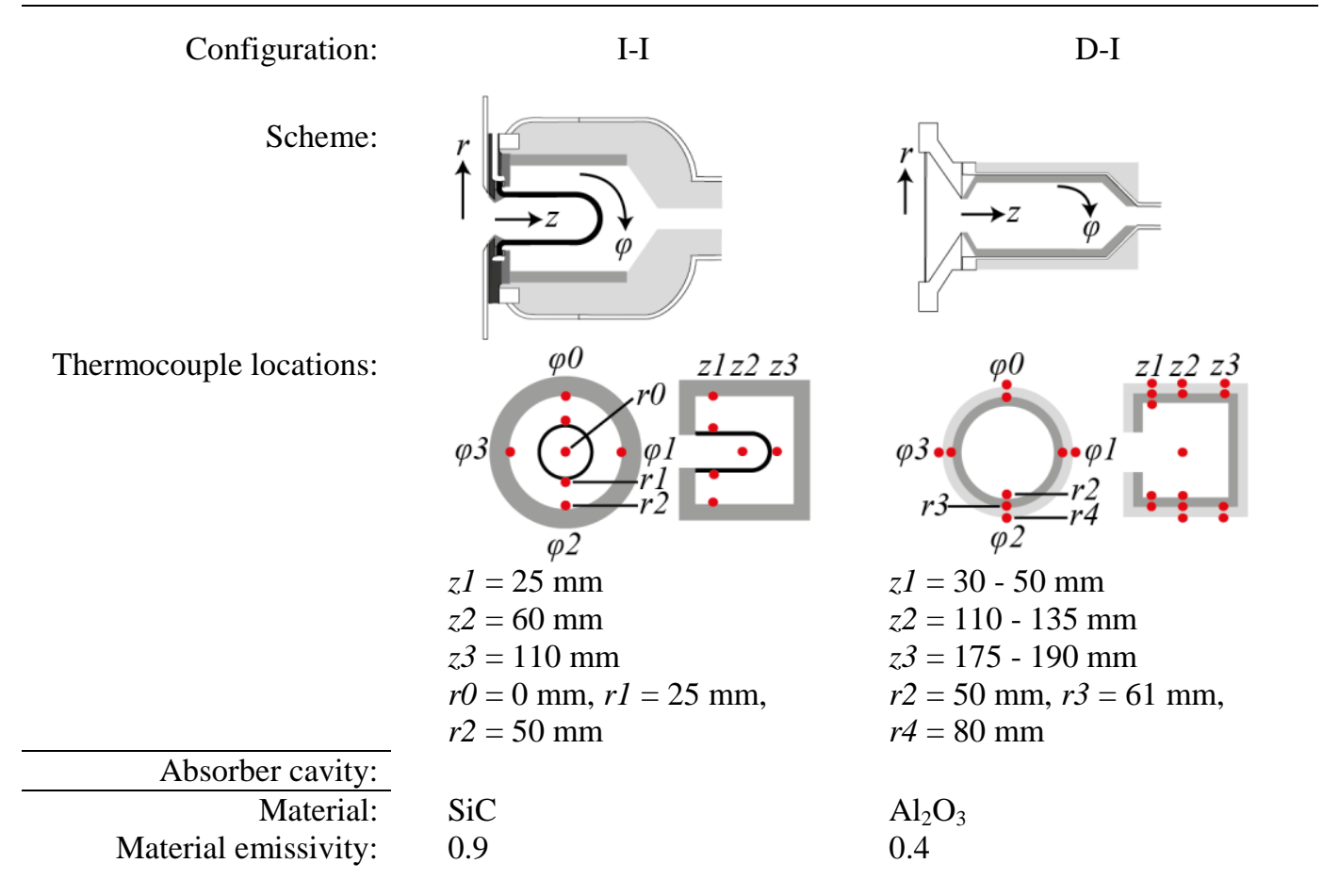




\begin{tabular}{|c|c|c|}
\hline Apparent absorptivity: & 0.988 & 0.93 \\
\hline Inner diameter: & $40 \mathrm{~mm}$ & $100 \mathrm{~mm}$ \\
\hline Outer diameter: & $50 \mathrm{~mm}$ & - \\
\hline Inner length & $95 \mathrm{~mm}$ & $200 \mathrm{~mm}$ \\
\hline Wall thickness & $5 \mathrm{~mm}$ & - \\
\hline \multicolumn{3}{|l|}{ Reactor chamber: } \\
\hline Diameter: & $100 \mathrm{~mm}$ & $100 \mathrm{~mm}$ \\
\hline Length: & $110 \mathrm{~mm}$ & $200 \mathrm{~mm}$ \\
\hline Volume & 0.81 & 1.61 \\
\hline Material: & $\mathrm{Al}_{2} \mathrm{O}_{3}-\mathrm{SiO}_{2}$ & $\mathrm{Al}_{2} \mathrm{O}_{3}$ \\
\hline \multicolumn{3}{|l|}{ Reactor shell: } \\
\hline Material: & Stainless steel & Inconel 601 \\
\hline Diameter: & $270 \mathrm{~mm}$ & $120 \mathrm{~mm}$ \\
\hline Thickness: & $5 \mathrm{~mm}$ & $1 \mathrm{~mm}$ \\
\hline Length: & $188 \mathrm{~mm}$ & $260 \mathrm{~mm}$ \\
\hline \multicolumn{3}{|l|}{ Front: } \\
\hline Material: & Inconel 601 & Aluminium \\
\hline Aperture diameter: & $30 \mathrm{~mm}$ & $50 \mathrm{~mm}$ \\
\hline Cooling: & Air-cooled & Water-cooled \\
\hline \multicolumn{3}{|l|}{ Thermal insulation: } \\
\hline Material: & $\mathrm{Al}_{2} \mathrm{O}_{3}-\mathrm{SiO}_{2}$ & $\mathrm{Al}_{2} \mathrm{O}_{3}-\mathrm{SiO}_{2}$ \\
\hline Thickness: & $78 \mathrm{~mm}$ & $20 \mathrm{~mm}$ \\
\hline Porosity: & $64 \%$ & $>70 \%$ \\
\hline \multicolumn{3}{|l|}{ Ceramic lining: } \\
\hline Material: & $\mathrm{SiO}_{2}-\mathrm{Al}_{2} \mathrm{O}_{3}$ & $\mathrm{Al}_{2} \mathrm{O}_{3}$ \\
\hline Thickness: & $10 \mathrm{~mm}$ & $10 \mathrm{~mm}$ \\
\hline Porosity: & $<30 \%$ & $38 \%$ \\
\hline \multicolumn{3}{|l|}{ Gas flow rates: } \\
\hline Vortex flow: & $2-15 \mathrm{~L}_{\mathrm{N}} / \mathrm{min}$ & $3 \mathrm{~L}_{\mathrm{N}} / \min$ \\
\hline Window protection: & - & $2 \mathrm{~L}_{\mathrm{N}} / \min$ \\
\hline Pressure rating: & $1-6$ bar & $1.1 \mathrm{bar}$ \\
\hline
\end{tabular}

Feedstock - Table 2 lists the ultimate (LECO CHNS- 932 \& RO-479), and proximate (Netzsch 409STA) analyses of activated charcoal (Fluka, Sigma-Aldrich 05120), which was used as the model carbonaceous feedstock. The particle size distribution, determined by laser scattering (HORIBA LA-950) was: $d_{\text {mean }}=42.25 \mu \mathrm{m}$ with $d_{\mathrm{v} 10}=9.39 \mu \mathrm{m}, d_{\mathrm{v} 50}=24.63 \mu \mathrm{m}$ (median), and $d_{\mathrm{v} 90}=99.30 \mu \mathrm{m}$. The lower heating value, determined based on the ultimate analysis [24], was $L H V_{\text {feedstock }}=29.33 \mathrm{MJ} / \mathrm{kg}$. A liquid slurry was prepared by mixing the charcoal with demineralized water to achieve a desired $\mathrm{H}_{2} \mathrm{O}: \mathrm{C}$ molar ratio. The slurry was injected at a desired charcoal feeding rate $\dot{m}_{\text {feedstock }}$ using a piston pump head (Ismatec QP Q2.CSC) and a peristaltic pump head (Ismatec MCP) for the I-I and D-I setups, respectively. 
Table 2 - Ultimate (dry and ash free basis) and proximate analyses of activated charcoal (Fluka, Sigma-Aldrich 05120).

\begin{tabular}{lll} 
Element & wt. \% & mole \% \\
$\mathrm{C}$ & 95.030 & 91.985 \\
$\mathrm{H}$ & 0.494 & 5.695 \\
$\mathrm{O}$ & 2.134 & 1.551 \\
$\mathrm{~S}$ & 0.749 & 0.271 \\
$\mathrm{~N}$ & 0.600 & 0.498 \\
\hline & & \\
Fixed carbon & 90.16 & - \\
Volatiles & 2.37 & - \\
Moisture & 1.62 & - \\
Ash & 5.83 & - \\
\hline
\end{tabular}

Experimental set-up - The experimental setup is shown in Figure 2. Experimentation was conducted at the high-flux solar simulator (HFSS) of ETH Zurich, which comprises an array of 7 high-pressure Xenon arcs, each close-coupled with truncated ellipsoidal specular reflectors, to provide an external source of intense thermal radiation - mostly in the visible and IR spectra - that closely approximates the heat transfer characteristics of highly concentrating solar systems [25]. The solar radiative input power $\dot{Q}_{\text {solar }}$ was measured optically on a Lambertian target with a calibrated CCD camera and verified with a water calorimeter. Temperatures were measured with type-K thermocouples at $z-r-\varphi$ locations indicated in the schemes of Table 1 . The nominal reactor temperature $T_{\text {reactor, }}$ the nominal shell temperature $T_{\text {shell, }}$ and the nominal cavity temperature $T_{\text {cavity }}$ (I-I configuration only) were calculated as average of the corresponding local measurements. For the D-I configuration, a two-color pyrometer (OMEGA iR2) was employed to measure $T_{\text {reactor }}$ immediately after the HFSS was turned off. A back-pressure valve (Tescom, 44-2500) was installed downstream and the pressure of the reactor chamber was monitored by a pressure transmitter (Keller, 33x). The gas mass flow rates were controlled by electronic flow controllers (Bronkhorst HI-TEC) calibrated for an accuracy of $\pm 1 \%$. The composition of 
gaseous products was analyzed on-line by infrared detectors (Siemens Calomat 6 and Ultramat; frequency $1 \mathrm{~Hz}$ ) and by gas chromatography (Varian Micro-GC; frequency $8 \mathrm{mHz}$ ). A pre-set flow rate of $\mathrm{N}_{2}$ (purity: $99.999 \%$ ) was introduced into the product gas stream as tracer for the determination of the molar flow rates of species. During a typical experimental run, the system was firstly heated to the desired temperature under inert gas flow (Ar; purity of $99.996 \%$ ) and then kept isothermally while feeding the reacting slurry. The main operational parameters were the solar radiative input power $\dot{Q}_{\text {solar }}$, the reactor's absolute pressure $p$, the charcoal feeding rate $\dot{m}_{\text {feedstock, }}$ the $\mathrm{H}_{2} \mathrm{O}: \mathrm{C}$ molar ratio, and the Ar mass flow rate $\dot{m}_{\text {Ar }}$ supporting the vortex flow. In selected runs, Ar was substituted by $\mathrm{CO}_{2}$ (purity: $99.998 \%$ ) to study its effect on the gasification. The measurement errors were evaluated based on the standard deviation error propagation [26]. Main source of uncertainty was in the measurement of the mass flow rate of the slurry because of particle deposition in the feeding system.

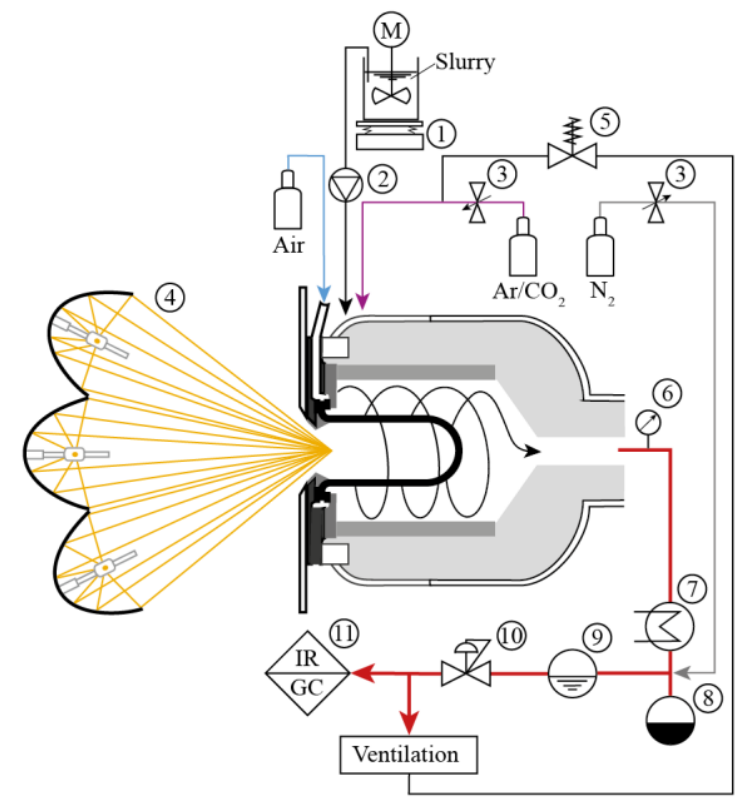

Figure 2 - Solar experimental setup: (1) scale, (2) slurry piston pump, (3) mass flow controllers, (4) high-flux solar simulator, (5) spring-over pressure valve, (6) pressure transmitter, (7) condenser, (8) steam trap, (9) scrubber, (10) back-pressure valve, (11) gas analysis. 


\section{Results and Discussion}

\subsection{The I-I solar reactor}

Table 3 lists the operating conditions and experimental results under approximately steadystate conditions for 51 solar experimental runs of the I-I solar reactor. The solar reactor was operated under the following range of parameters: $p=1.0-5.9$ bar, $\dot{m}_{\mathrm{Ar}}=2-15 \mathrm{~L}_{\mathrm{N}} / \mathrm{min}$, $\dot{m}_{\text {feedstock }}=0.42-1.26 \mathrm{~g} / \mathrm{min}, \mathrm{H}_{2} \mathrm{O}: \mathrm{C}$ molar ratio $=1.48-1.98$ (accounting for the moisture content in the charcoal), and $\dot{Q}_{\text {solar }}=1.3-2.6 \mathrm{~kW}$, which corresponds to mean solar concentration ratios ${ }^{*}$ over the aperture in the range $C=1794-3718$ suns. The highest $T_{\text {reactor }}$ was $1273{ }^{\circ} \mathrm{C}$, and $T_{\text {cavity }}$ was $155 \mathrm{~K}$ higher on average. The highest operational pressure tested was 5.9 bar. Both $T_{\text {cavity }}$ and $p$ were mainly limited by the integrity of the SiC cavity. The nominal residence time of the reactants $\tau$ was calculated using [20]:

$$
\tau=\frac{p V}{R T_{\text {reactor }}}\left(\dot{n}_{\mathrm{Ar}}+\dot{n}_{\mathrm{H}_{2} \mathrm{O}}+\dot{n}_{\mathrm{C}}\left(1+\frac{X_{C}}{\ln \left(1-X_{C}\right)}\right)\right)^{-1}
$$

where $V$ is the volume of the reactor, $R$ the universal gas constant, $\dot{n}$ the molar flow rate, and $X_{\mathrm{C}}$ the final extent of carbon conversion,

$$
X_{\mathrm{C}}=\frac{\dot{n}_{\mathrm{CO}}+\dot{n}_{\mathrm{CO}_{2}}}{\dot{n}_{\mathrm{C}}}
$$

For all runs of Table $3, \tau$ was in the range $0.7-4.6 \mathrm{~s}$. Note that since $X_{\mathrm{C}}<1$ (incomplete conversion), only the converted feedstock was accounted in Eqs. (2) and (3). The peak values of the performance indicators obtained were: $X_{\mathrm{C}}=94.4 \%, \eta_{\text {solar-to-fuel }}=19.7 \%$, and $U=1.35$.

\footnotetext{
\$ The solar concentration ratio $C$ is defined as the mean solar radiative flux over the solar reactor's aperture, normalized to the direct normal solar irradiation.
} 
Table 3 - Operating conditions for the I-I solar reactor and experimentally measured key

parameters under approximately steady-state conditions.

\begin{tabular}{|c|c|c|c|c|c|c|c|c|c|c|c|c|c|c|}
\hline$\#$ & $\begin{array}{l}\dot{Q}_{\text {solar }} \\
{[\mathrm{W}]}\end{array}$ & $\begin{array}{l}p \\
{[\mathrm{bar}]}\end{array}$ & $\begin{array}{l}\dot{m}_{\mathrm{Ar}} \\
{\left[\mathrm{L}_{\mathrm{N}} /\right.} \\
\min ]\end{array}$ & $\begin{array}{l}\dot{m}_{\text {feedstock }} \\
{[\mathrm{g} / \mathrm{min}]}\end{array}$ & $\mathrm{H}_{2} \mathrm{O}: \mathrm{C}$ & $\begin{array}{l}T_{\text {reactor }} \\
{\left[{ }^{\circ} \mathrm{C}\right]}\end{array}$ & $\begin{array}{l}T_{\text {cavity }} \\
{\left[{ }^{\circ} \mathrm{C}\right]}\end{array}$ & $\begin{array}{l}\dot{n}_{\mathrm{H}_{2}} \\
{[\mathrm{mmol} /} \\
\text { min] }\end{array}$ & $\begin{array}{l}\dot{n}_{\mathrm{CO}} \\
{[\mathrm{mmol} /} \\
\mathrm{min}]\end{array}$ & $\begin{array}{l}\dot{n}_{\mathrm{CO}_{2}} \\
{[\mathrm{mmol} /} \\
\mathrm{min}]\end{array}$ & $\begin{array}{l}\tau \\
{[\mathrm{s}]}\end{array}$ & $\begin{array}{l}X_{\mathrm{C}} \\
{[\%]}\end{array}$ & $\begin{array}{l}\eta_{\text {solar-to-fuel }} \\
{[\%]}\end{array}$ & $U$ \\
\hline 1 & 1546 & 1.0 & 4.0 & 0.48 & 1.48 & 1105 & 1248 & 19.4 & 12.6 & 3.4 & 1.9 & 45.2 & 8.3 & 1.20 \\
\hline 2 & 1268 & 1.0 & 4.0 & 0.48 & 1.48 & 1010 & 1159 & 12.8 & 11.0 & 0.9 & 2.0 & 34.2 & 7.7 & 1.18 \\
\hline 3 & 1971 & 1.0 & 4.0 & 0.50 & 1.48 & 1196 & 1351 & 35.7 & 29.1 & 3.3 & 1.6 & 89.2 & 12.9 & 1.23 \\
\hline 4 & 1891 & 1.0 & 4.0 & 0.68 & 1.48 & 1185 & 1333 & 23.5 & 14.1 & 4.7 & 1.6 & 37.9 & 8.0 & 1.22 \\
\hline 5 & 1934 & 1.0 & 4.0 & 0.91 & 1.48 & 1195 & 1338 & 38.4 & 24.7 & 6.9 & 1.4 & 47.5 & 12.5 & 1.21 \\
\hline 6 & 1934 & 1.0 & 7.5 & 0.91 & 1.48 & 1191 & 1338 & 30.8 & 19.1 & 5.8 & 0.9 & 37.6 & 10.1 & 1.23 \\
\hline 7 & 1934 & 1.0 & 11.0 & 0.93 & 1.48 & 1184 & 1331 & 27.9 & 18.3 & 4.8 & 0.7 & 34.0 & 9.4 & 1.20 \\
\hline 8 & 1915 & 1.0 & 2.0 & 0.88 & 1.48 & 1204 & 1351 & 41.0 & 26.0 & 7.5 & 2.0 & 51.8 & 13.5 & 1.17 \\
\hline 9 & 1671 & 1.0 & 4.0 & 0.62 & 1.73 & 1090 & 1218 & 25.8 & 18.2 & 3.8 & 1.7 & 48.6 & 10.5 & 1.21 \\
\hline 10 & 2085 & 1.0 & 4.0 & 0.56 & 1.73 & 1214 & 1378 & 41.6 & 29.1 & 6.2 & 1.5 & 86.8 & 13.0 & 1.21 \\
\hline 11 & 2238 & 1.0 & 4.0 & 0.56 & 1.73 & 1270 & 1439 & 39.6 & 27.1 & 6.2 & 1.5 & 81.9 & 11.4 & 1.20 \\
\hline 12 & 2238 & 1.0 & 4.0 & 1.12 & 1.73 & 1256 & 1324 & 76.2 & 46.8 & 14.7 & 1.1 & 74.8 & 19.7 & 1.18 \\
\hline 13 & 2154 & 1.0 & 4.0 & 0.85 & 1.73 & 1255 & 1418 & 50.8 & 31.5 & 9.6 & 1.3 & 66.1 & 14.3 & 1.18 \\
\hline 14 & 1965 & 1.0 & 4.0 & 0.80 & 1.73 & 1202 & 1366 & 45.0 & 26.5 & 9.3 & 1.4 & 61.2 & 13.7 & 1.18 \\
\hline 15 & 1965 & 1.0 & 5.0 & 0.85 & 1.73 & 1199 & 1364 & 43.9 & 26.1 & 8.9 & 1.2 & 56.5 & 13.5 & 1.20 \\
\hline 16 & 1965 & 1.0 & 6.0 & 0.90 & 1.73 & 1197 & 1268 & 39.8 & 23.4 & 8.2 & 1.0 & 47.9 & 12.3 & 1.22 \\
\hline 17 & 1965 & 1.0 & 3.0 & 0.77 & 1.73 & 1202 & 1365 & 48.3 & 28.8 & 9.8 & 1.6 & 68.1 & 14.9 & 1.16 \\
\hline 18 & 1965 & 1.0 & 2.0 & 0.77 & 1.73 & 1202 & 1365 & 48.5 & 28.6 & 9.9 & 2.0 & 68.3 & 14.8 & 1.17 \\
\hline 19 & 1649 & 1.0 & 4.0 & 0.81 & 1.73 & 1118 & 1270 & 40.2 & 27.2 & 6.5 & 1.5 & 56.5 & 15.4 & 1.21 \\
\hline 20 & 1411 & 1.0 & 4.0 & 0.82 & 1.73 & 1035 & 1189 & 27.5 & 22.6 & 2.5 & 1.6 & 41.6 & 13.7 & 1.20 \\
\hline 21 & 1316 & 1.0 & 4.0 & 0.70 & 1.73 & 1030 & 1192 & 22.1 & 18.5 & 1.8 & 1.7 & 39.3 & 12.0 & 1.19 \\
\hline 22 & 1737 & 1.0 & 4.0 & 0.62 & 1.73 & 1149 & 1305 & 41.1 & 31.4 & 4.9 & 1.5 & 79.3 & 15.8 & 1.23 \\
\hline 23 & 1465 & 1.0 & 4.0 & 0.69 & 1.98 & 1022 & 1117 & 18.1 & 14.6 & 1.8 & 1.6 & 32.1 & 9.0 & 1.16 \\
\hline 24 & 1465 & 1.0 & 4.0 & 0.42 & 1.98 & 1039 & 1133 & 20.8 & 16.9 & 2.0 & 1.9 & 61.2 & 10.3 & 1.19 \\
\hline 25 & 1909 & 1.0 & 4.0 & 0.54 & 1.98 & 1186 & 1297 & 41.9 & 29.7 & 6.0 & 1.5 & 89.9 & 14.1 & 1.20 \\
\hline 26 & 2245 & 1.0 & 4.0 & 0.54 & 1.98 & 1273 & 1405 & 41.8 & 30.4 & 5.7 & 1.4 & 90.7 & 12.1 & 1.22 \\
\hline 27 & 1949 & 1.9 & 4.0 & 0.99 & 1.73 & 1009 & 1168 & 14.4 & 8.7 & 2.8 & 3.0 & 16.0 & 4.9 & 1.22 \\
\hline 28 & 2397 & 1.9 & 4.0 & 0.83 & 1.73 & 1199 & 1360 & 68.0 & 38.0 & 15.0 & 2.4 & 86.8 & 16.0 & 1.19 \\
\hline 29 & 1885 & 1.9 & 4.0 & 0.96 & 1.73 & 1088 & 1211 & 31.9 & 16.5 & 6.8 & 2.7 & 33.3 & 10.1 & 1.31 \\
\hline 30 & 2026 & 1.9 & 4.0 & 0.96 & 1.73 & 1086 & 1205 & 50.4 & 30.3 & 10.0 & 2.6 & 57.8 & 15.8 & 1.22 \\
\hline 31 & 2022 & 3.1 & 4.0 & 0.87 & 1.73 & 1112 & 1240 & 18.5 & 9.4 & 3.4 & 4.6 & 20.1 & 5.6 & 1.35 \\
\hline 32 & 2245 & 3.1 & 4.0 & 0.83 & 1.73 & 1142 & 1381 & 40.1 & 24.5 & 7.0 & 4.4 & 51.7 & 11.5 & 1.31 \\
\hline 33 & 2524 & 3.0 & 4.0 & 0.83 & 1.73 & 1166 & 1333 & 48.9 & 30.6 & 9.0 & 4.1 & 65.2 & 12.0 & 1.28 \\
\hline 34 & 2385 & 1.0 & 8.0 & 0.90 & 1.73 & 1132 & 1334 & 36.4 & 21.1 & 7.4 & 0.9 & 43.0 & 9.5 & 1.28 \\
\hline 35 & 2453 & 2.1 & 8.0 & 0.99 & 1.73 & 1153 & 1346 & 48.6 & 25.0 & 11.3 & 1.7 & 50.0 & 11.6 & 1.28 \\
\hline 36 & 2453 & 3.1 & 8.0 & 0.97 & 1.73 & 1162 & 1348 & 52.1 & 26.9 & 12.0 & 2.6 & 54.6 & 12.4 & 1.28 \\
\hline 37 & 2453 & 3.9 & 8.0 & 0.99 & 1.73 & 1167 & 1348 & 51.0 & 26.2 & 11.6 & 3.3 & 51.9 & 12.1 & 1.29 \\
\hline 38 & 2453 & 5.0 & 8.0 & 0.83 & 1.73 & 1180 & 1351 & 35.8 & 14.7 & 9.3 & 4.3 & 39.5 & 8.3 & 1.31 \\
\hline 39 & 2219 & 1.0 & 3.0 & 0.63 & 1.73 & 1173 & 1342 & 31.4 & 16.5 & 7.5 & 1.9 & 52.2 & 8.7 & 1.18 \\
\hline 40 & 2261 & 1.0 & 3.0 & 0.78 & 1.73 & 1161 & 1327 & 40.1 & 21.3 & 9.4 & 1.7 & 54.1 & 10.9 & 1.23 \\
\hline
\end{tabular}




$\begin{array}{rllllllllllllll}41 & 2290 & 2.0 & 6.0 & 0.74 & 1.73 & 1158 & 1323 & 40.0 & 21.4 & 8.9 & 2.2 & 56.4 & 10.7 & 1.28 \\ 42 & 2400 & 3.0 & 9.0 & 0.66 & 1.73 & 1179 & 1341 & 42.6 & 23.9 & 8.7 & 2.5 & 67.1 & 11.1 & 1.30 \\ 43 & 2400 & 3.9 & 12.0 & 0.63 & 1.73 & 1178 & 1333 & 45.3 & 28.3 & 8.3 & 2.6 & 79.0 & 11.9 & 1.28 \\ 44 & 2400 & 4.9 & 15.0 & 0.67 & 1.73 & 1169 & 1322 & 45.7 & 29.1 & 8.3 & 2.6 & 75.9 & 12.1 & 1.27 \\ 45 & 2400 & 5.9 & 15.0 & 0.65 & 1.73 & 1164 & 1314 & 43.2 & 27.2 & 8.0 & 3.2 & 74.3 & 11.5 & 1.26 \\ 46 & 2400 & 4.0 & 12.0 & 0.93 & 1.73 & 1167 & 1322 & 60.9 & 36.9 & 11.6 & 2.5 & 71.1 & 15.4 & 1.28 \\ 47 & 2400 & 4.0 & 12.0 & 1.26 & 1.73 & 1158 & 1314 & 65.2 & 37.2 & 13.7 & 2.3 & 55.2 & 15.3 & 1.26 \\ 48 & 2346 & 1.0 & 3.0 * & 0.77 & 1.73 & 1157 & 1342 & 16.7 & 45.5 & 122.1 & 1.7 & 59.3 & 10.9 & 1.27 \\ 49 & 2346 & 2.0 & 6.0 * & 0.77 & 1.73 & 1135 & 1332 & 10.2 & 56.9 & 245.9 & 2.2 & 61.3 & 12.0 & 1.33 \\ 50 & 2448 & 3.0 & 9.0 * & 0.77 & 1.73 & 1119 & 1317 & 8.0 & 69.0 & 373.8 & 2.5 & 72.1 & 13.2 & 1.31 \\ 51 & 2628 & 3.9 & 12.0 * & 0.77 & 1.73 & 1120 & 1314 & 6.6 & 78.8 & 510.6 & 2.5 & 94.4 & 13.4 & 1.18\end{array}$

Figure 3a presents a representative experimental run conducted with the I-I solar reactor at ambient pressure. Plotted are the temporal variations of $\dot{m}_{\text {feedstock }}, \dot{Q}_{\text {solar }}, T_{\text {cavity }}, T_{\text {reactor }}, T_{\text {offgas }}$, and the product gas evolution. The period of the experiment considered to approximate steady-state conditions is indicated by the two vertical dotted lines. For this run, these conditions were: $p=1$ bar, $\dot{m}_{\mathrm{Ar}}=4 \mathrm{~L}_{\mathrm{N}} / \mathrm{min}, \dot{m}_{\text {feedstock }}=0.54 \mathrm{~g} / \mathrm{min}, \mathrm{H}_{2} \mathrm{O}: \mathrm{C}=1.98$, and $\dot{Q}_{\text {solar }}=$ $1.9 \mathrm{~kW}$, leading to $T_{\text {cavity }}=1297^{\circ} \mathrm{C}, T_{\text {reactor }}=1186^{\circ} \mathrm{C}, T_{\text {offgas }}=953^{\circ} \mathrm{C}$, and yielding a syngas flow of $\dot{n}_{\mathrm{H}_{2}}=41.9 \mathrm{mmol} / \mathrm{min}, \dot{n}_{\mathrm{CO}}=29.7 \mathrm{mmol} / \mathrm{min}$, and $\dot{n}_{\mathrm{CO}_{2}}=6 \mathrm{mmol} / \mathrm{min}$. The performance indicators obtained were: $X_{\mathrm{C}}=89.9 \%$ within $\tau=1.5 \mathrm{~s}, \eta_{\text {solar-to-fuel }}=14.1 \%$, and $U$ $=1.20$. 

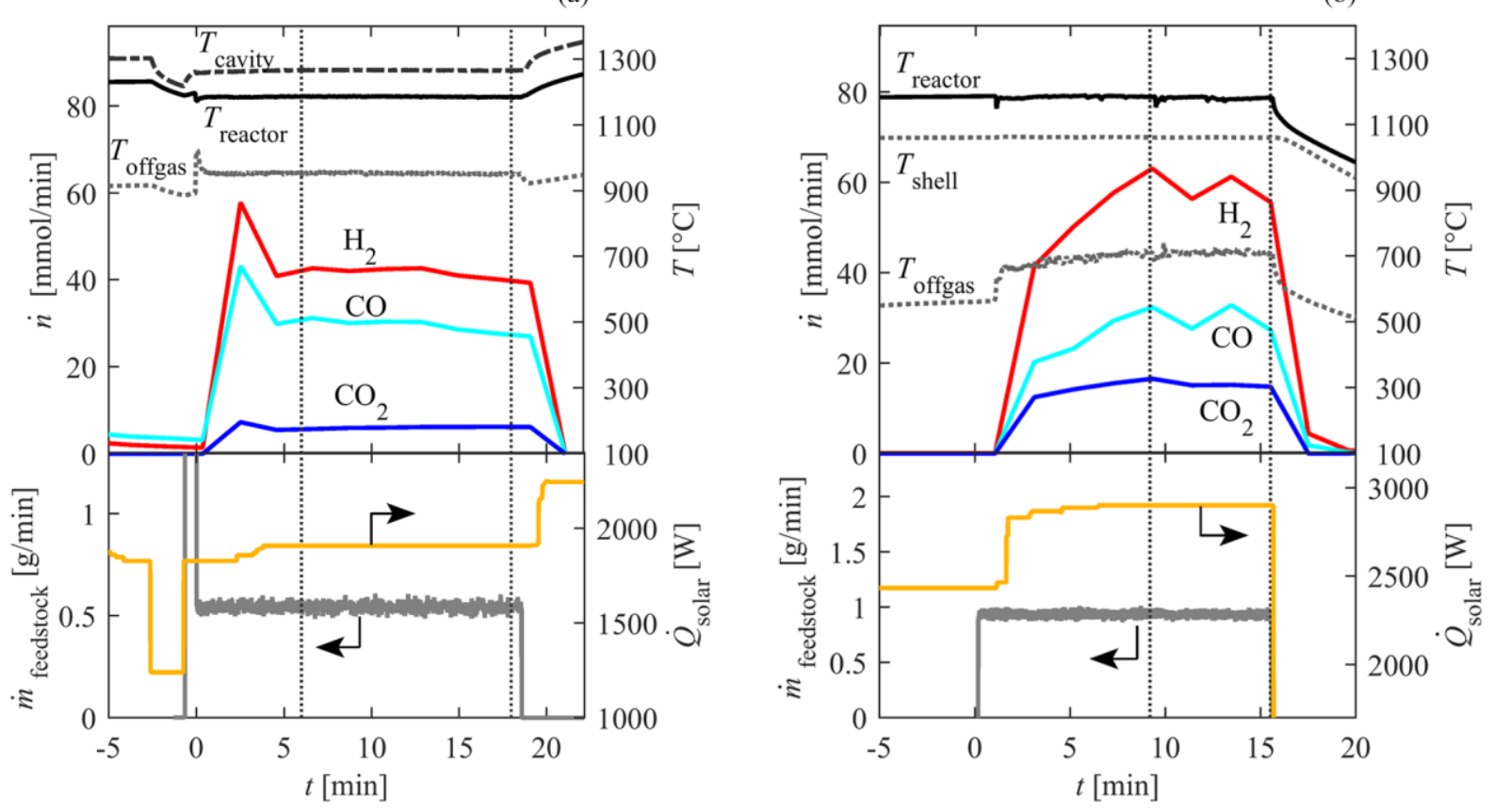

Figure 3 - Representative solar experimental run conducted at $p=1$ bar with: a) the I-I solar reactor; b) the D-I solar reactor.

Figure 4 presents $\dot{n}$ for the species $\mathrm{H}_{2}(\bullet), \mathrm{CO}(\Delta)$, and $\mathrm{CO}_{2}(\bullet)$ as a function of $T_{\text {reactor }}$ at $p=$ 1.0 bar and $\dot{m}_{\mathrm{Ar}}=4 \mathrm{~L}_{\mathrm{N}} / \mathrm{min}$, and for three slurry compositions: a) $\dot{m}_{\text {feedstock }}=0.49 \pm 0.02 \mathrm{~g} / \mathrm{min}$, $\left.\mathrm{H}_{2} \mathrm{O}: \mathrm{C}=1.48 ; \mathrm{b}\right) \dot{m}_{\text {feedstock }}=0.61 \pm 0.05 \mathrm{~g} / \mathrm{min}, \mathrm{H}_{2} \mathrm{O}: \mathrm{C}=1.73 ;$ and c) $\dot{m}_{\text {feedstock }}=0.55 \pm 0.10$ g/min, $\mathrm{H}_{2} \mathrm{O}: \mathrm{C}=1.98$, (Figure $4 \mathrm{a}, \mathrm{b}$, c respectively). High-quality syngas containing low molar fraction of $\mathrm{CO}_{2}$ was obtained, with $\dot{n}_{\text {syngas }}$ increasing with $T_{\text {reactor. }}$ The presence of $\mathrm{CH}_{4}$ was found to be negligible $\left(\dot{n}_{\mathrm{CH}_{4}}<1.19 \mathrm{mmol} / \mathrm{min}\right)$ and detected only in 5 out of 51 experimental runs, partly because of the low volatile fraction in the charcoal as $\mathrm{CH}_{4}$ is typically generated during pyrolysis [27]. In a representative sample retrieved from the offgas system, no tars were detected, which was attributed to the de-volatilized charcoal and the high gasification temperatures. 


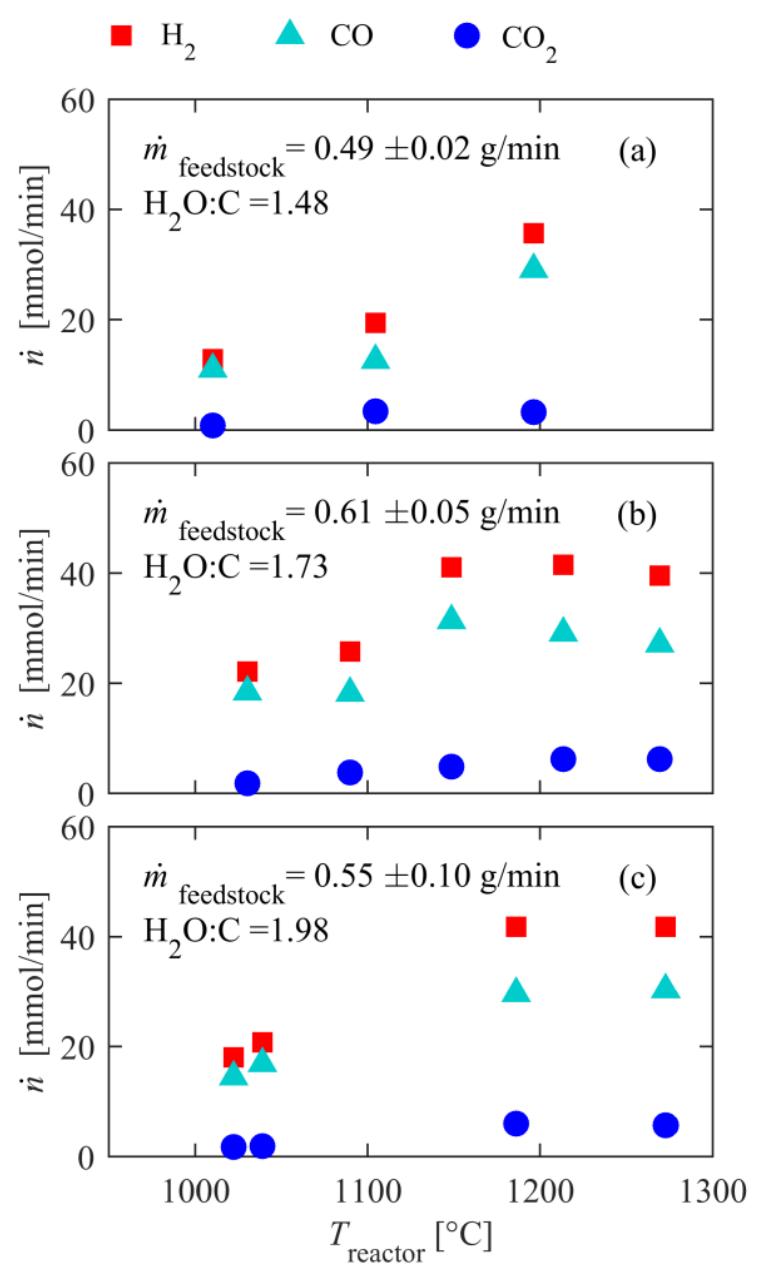

Figure 4 - Molar flow rate for the product gas species $\mathrm{H}_{2}(\varpi), \mathrm{CO}(\Delta)$, and $\mathrm{CO}_{2}(\bullet)$ for three slurry compositions $(\mathrm{a}, \mathrm{b}, \mathrm{c})$ as a function of $T_{\text {reactor }}$, obtained with the I-I solar reactor at $p=1$ bar.

Figure 5 presents: $X_{\mathrm{C}}(\mathrm{a}), \eta_{\text {solar-to-fuel }}(\mathrm{b}), U(\mathrm{c})$, and $\mathrm{H}_{2}: \mathrm{CO}$ molar ratio of the syngas produced (d) as a function of $T_{\text {reactor }}$ for $p=1.0$ bar and $\dot{m}_{\mathrm{Ar}}=4 \mathrm{~L}_{\mathrm{N}} / \mathrm{min}$, and for three slurry compositions: $\dot{m}_{\text {feedstock }}=0.49 \pm 0.02 \mathrm{~g} / \mathrm{min}$ with $\mathrm{H}_{2} \mathrm{O}: \mathrm{C}=1.48(\boldsymbol{\bullet}) ; \dot{m}_{\text {feedstock }}=0.61 \pm 0.05$ g/min with $\mathrm{H}_{2} \mathrm{O}: \mathrm{C}=1.73(\Delta)$; and $\dot{m}_{\text {feedstock }}=0.55 \pm 0.10 \mathrm{~g} / \mathrm{min}$ with $\mathrm{H}_{2} \mathrm{O}: \mathrm{C}=1.98(\bullet)$. The reaction extent increases monotonically with $T_{\text {reactor }}$ and leveled at $90.7 \%$ for $T_{\text {reactor }}>1180$ ${ }^{\circ} \mathrm{C}$. The dependence of $X_{\mathrm{C}}$ on $\mathrm{H}_{2} \mathrm{O}: \mathrm{C}$ stoichiometry is inconclusive, partly because of competing effects of higher $p_{\mathrm{H}_{2} \mathrm{O}}$ leading to faster reaction rates versus shorter $\tau$ as the $\mathrm{H}_{2} \mathrm{O}: \mathrm{C}$ molar ratio is increased. Excess steam also leads to a higher sensible heat sink. Similarly, a 
peak in $\eta_{\text {solar-to-fuel }}$ at $15.8 \%$ for $1150{ }^{\circ} \mathrm{C}$ can be explained by the increase in $X_{\mathrm{C}}$ with $T_{\text {reactor }}$ at the expense of higher conductive and radiative heat losses. Occasional clogging of the feeding system was observed with the $\mathrm{H}_{2} \mathrm{O}: \mathrm{C}$ molar ratio of 1.48 , and thus experimentation was continued only with the higher $\mathrm{H}_{2} \mathrm{O}: \mathrm{C}$ molar ratios. The $\mathrm{H}_{2}: \mathrm{CO}$ molar ratio varied within the range $1.16-1.54$ with $T_{\text {reactor }}$, presumably as a result of the off-gas stream undergoing the water-gas shift reaction at the exit of the solar reactor prior to sampling [28]. The averaged value of $U$ for this set of experiments was found to be $1.20 \pm 0.06$. Note that, in contrast to $X_{\mathrm{C}}$, $U$ is less sensitive to $T_{\text {reactor }}$ because it considers only the calorific upgrade of the converted feedstock. 
- $\dot{m}_{\text {feedstock }}=0.49 \pm 0.02 \mathrm{~g} / \mathrm{min}, \mathrm{H}_{2} \mathrm{O}: \mathrm{C}=1.48$

$\Delta \quad \dot{m}_{\text {feedstock }}=0.61 \pm 0.05 \mathrm{~g} / \mathrm{min}, \mathrm{H}_{2} \mathrm{O}: \mathrm{C}=1.73$

$\dot{m}_{\text {feedstock }}=0.55 \pm 0.10 \mathrm{~g} / \mathrm{min}, \mathrm{H}_{2} \mathrm{O}: \mathrm{C}=1.98$
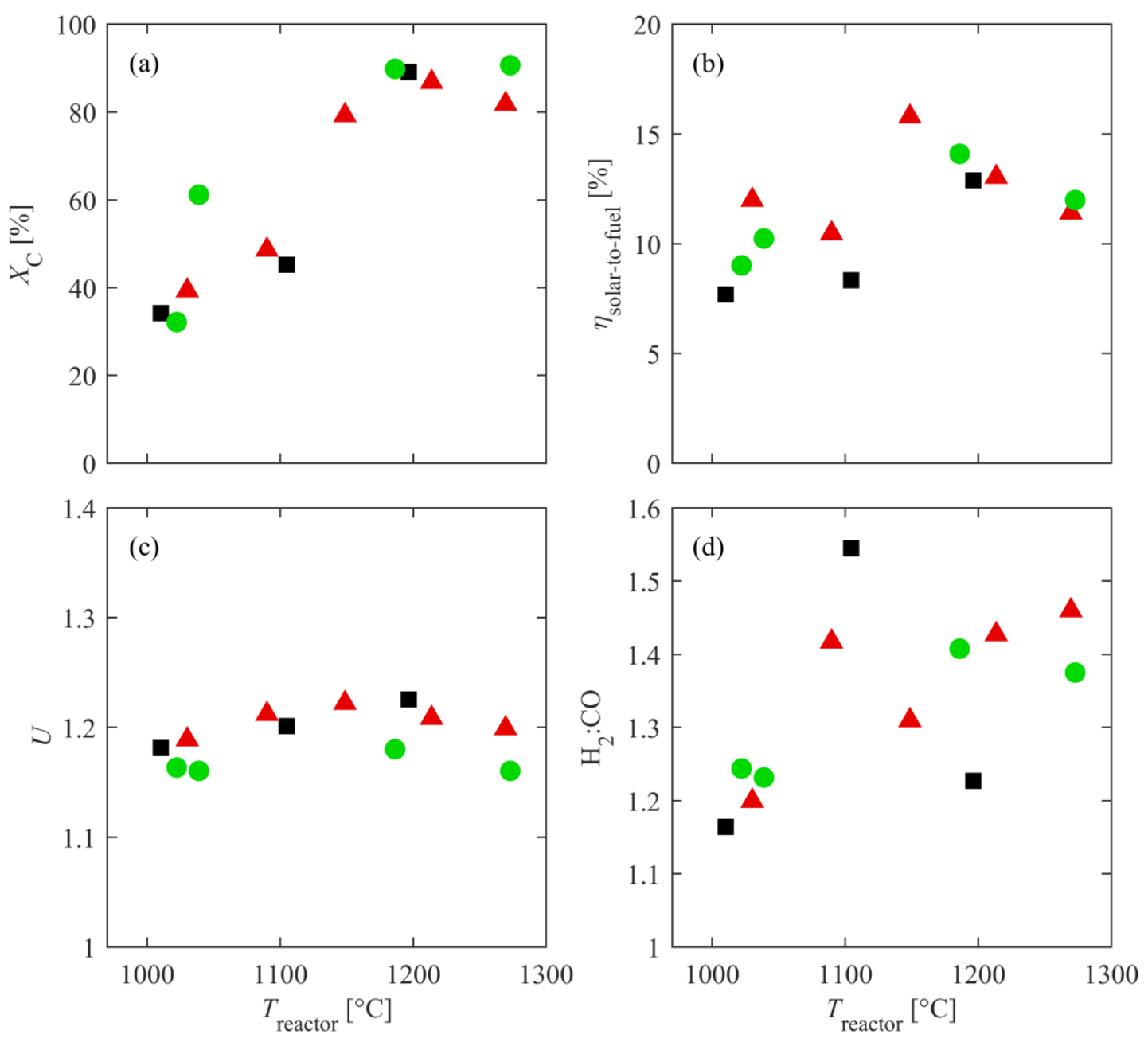

Figure 5 - a) Reaction extent, b) solar-to-fuel energy conversion efficiency, c) energetic upgrade factor, and d) $\mathrm{H}_{2}: \mathrm{CO}$ molar ratio as a function of $T_{\text {reactor }}$ for three slurry compositions: $\dot{m}_{\text {feedstock }}=0.49 \pm 0.02 \mathrm{~g} / \mathrm{min}$ with $\mathrm{H}_{2} \mathrm{O}: \mathrm{C}=1.48(\boldsymbol{\Xi}) ; \dot{m}_{\text {feedstock }}=0.61 \pm 0.05 \mathrm{~g} / \mathrm{min}$ with $\mathrm{H}_{2} \mathrm{O}: \mathrm{C}$ $=1.73(\Delta) ; \dot{m}_{\text {feedstock }}=0.55 \pm 0.10 \mathrm{~g} / \mathrm{min}$ with $\mathrm{H}_{2} \mathrm{O}: \mathrm{C}=1.98(\bullet)$, obtained with the I-I solar reactor at $p=1$ bar.

The input value of $\dot{m}_{\mathrm{Ar}}$ was varied to control $\tau$ and $p_{\mathrm{H}_{2} \mathrm{O}}$. Figure 6 presents $X_{\mathrm{C}}$ and $\eta_{\text {solar-to-fuel }}$ as a function of $\tau$ and $p_{\mathrm{H}_{2} \mathrm{O}}$ for $\dot{m}_{\mathrm{Ar}}=11.0,7.5,4.0,2.0 \mathrm{~L}_{\mathrm{N}} / \mathrm{min}$ ((a) to (d), respectively). The experimental conditions were: $p=1.0$ bar, $\dot{m}_{\text {feedstock }}=0.91 \pm 0.05 \mathrm{~g} / \mathrm{min}, \mathrm{H}_{2} \mathrm{O}: \mathrm{C}=1.48$, and 
$T_{\text {reactor }}=1193 \pm 10{ }^{\circ} \mathrm{C}$. The corresponding Ar inlet velocity $u_{\mathrm{Ar}, \mathrm{i}}=25.4,17.1,9.0,4.7 \mathrm{~m} / \mathrm{s}$ provided a qualitative measure for particle entrainment by the vortex flow since the drag force acting on a particle is proportional to $u_{\mathrm{Ar}, \mathrm{i}}^{2}$. As $\dot{m}_{\mathrm{Ar}}$ was lowered from 11 to $2 \mathrm{~L}_{\mathrm{N}} / \mathrm{min}, \tau$ and $p_{\mathrm{H}_{2} \mathrm{O}}$ increased leading to higher values of $X_{\mathrm{C}}$, but approaching a constant value because of insufficient particle entrainment (particle drop-out) for $u_{\mathrm{Ar}, \mathrm{i}}<10 \mathrm{~m} / \mathrm{s}$, as verified by particle deposition inside the reaction chamber. It can be seen that $\eta_{\text {solar-to-fuel }}$ follows the same trend because of higher reaction extent and less energy wasted in heating Ar.

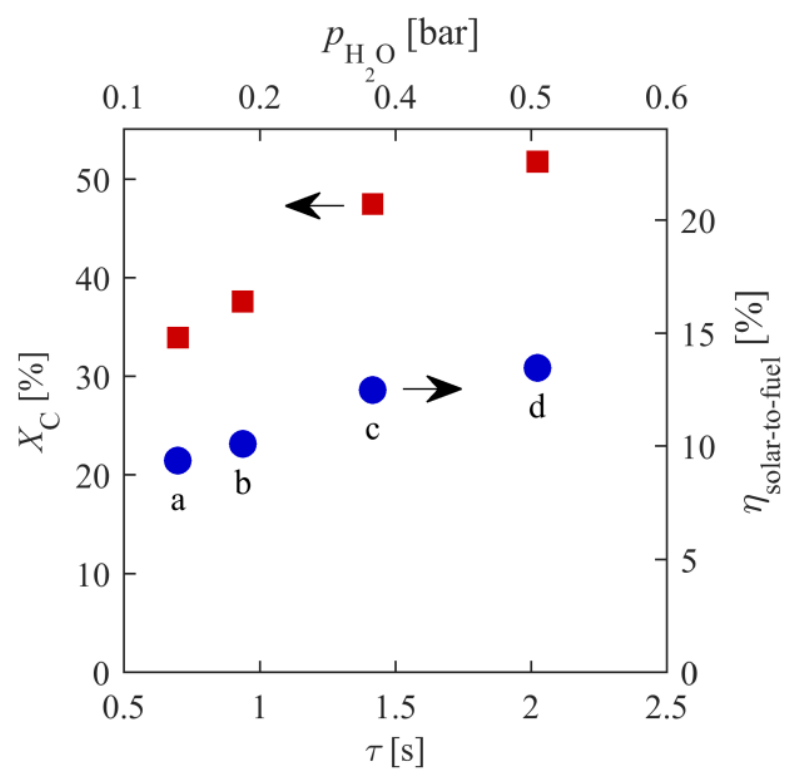

Figure 6 - Reaction extent and solar-to-fuel energy conversion efficiency as a function of nominal residence time and $p_{\mathrm{H}_{2} \mathrm{O}}$ for $\dot{m}_{\mathrm{Ar}}=11.0,7.5,4.0,2.0 \mathrm{~L}_{\mathrm{N}} / \mathrm{min}((\mathrm{a})$ to (d), respectively), obtained with the I-I solar reactor. Experimental conditions: $p=1.0$ bar, $\dot{m}_{\text {feedstock }}=0.91 \pm 0.05$ $\mathrm{g} / \mathrm{min}, \mathrm{H}_{2} \mathrm{O}: \mathrm{C}=1.48, T_{\text {reactor }}=1193 \pm 10{ }^{\circ} \mathrm{C}$.

Figure 7 presents $X_{\mathrm{C}}$ as a function of $T_{\text {reactor }}$ for $\dot{m}_{\mathrm{Ar}}=4 \mathrm{~L}_{\mathrm{N}} / \mathrm{min}, \dot{m}_{\text {feedstock }}=0.87 \pm 0.05 \mathrm{~g} / \mathrm{min}$, and $\mathrm{H}_{2} \mathrm{O}: \mathrm{C}=1.73$ and for three pressure levels: $p=1.0,1.9$, and 3.1 bar. For all 3 pressures, $X_{\mathrm{C}}$ monotonically increases with $T_{\text {reactor }}$ in a manner that is approximately linear over the measured range. With increasing $p$, the fit becomes steeper in accordance with Le Chatelier's principle for Eq. (1), i.e., higher pressures shift the thermodynamic equilibrium composition 
to higher temperatures. The intersection around $T_{\text {reactor }}=1120{ }^{\circ} \mathrm{C}$ points out to non-linear competing effects as $X_{\mathrm{C}}$ either decreases or increases with pressure at above or below that temperature, presumably due to change in the swirl number which affects the actual residence time [29].

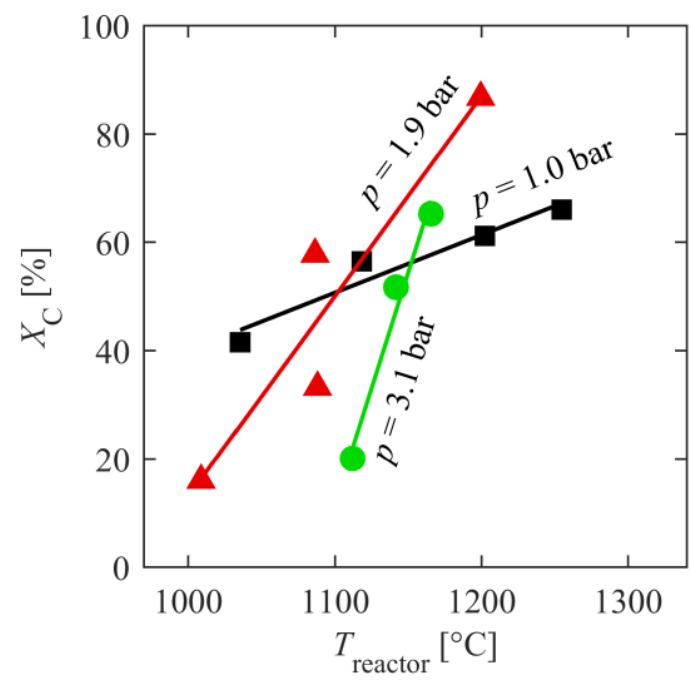

Figure 7 - Reaction extent as a function of $T_{\text {reactor }}$ for $p=1.0$ bar $(\boldsymbol{\square}), 1.9$ bar $(\boldsymbol{\Delta})$, and 3.1 bar (•), obtained with the I-I solar reactor. Experimental conditions: $\dot{m}_{\mathrm{Ar}}=4 \mathrm{~L}_{\mathrm{N}} / \mathrm{min}, \dot{m}_{\text {feedstock }}=$ $0.87 \pm 0.05 \mathrm{~g} / \mathrm{min}$, and $\mathrm{H}_{2} \mathrm{O}: \mathrm{C}=1.73$.

Figure 8 presents $X_{\mathrm{C}}(\mathrm{a}), \eta_{\text {solar-to-fuel }}(\mathrm{b}), U(\mathrm{c}), \tau(\mathrm{d}), \mathrm{H}_{2}$ : $\mathrm{CO}$ molar ratio (e), and $\mathrm{CO}_{2}: \mathrm{CO}$ molar ratio (f) are plotted as function of $p$ in the range $1-6$ bar and for three different vortex flow settings: $\dot{m}_{\mathrm{Ar}}=8 \mathrm{~L}_{\mathrm{N}} / \min (\mathbf{\Delta}) ; \dot{m}_{\mathrm{Ar}, \mathrm{gi}}=3,6,9,12,15,15 \mathrm{~L}_{\mathrm{N}} / \min$ for $p=1,2,3,4,5,6$ bar, respectively $(\bullet)$; and $\dot{m}_{\mathrm{CO}_{2}, \mathrm{gi}}=3,6,9,12 \mathrm{~L}_{\mathrm{N}} / \mathrm{min}$ for $p=1,2,3,4$ bar, respectively $(\square)$. For these runs, $\dot{m}_{\text {feedstock }}=0.79 \pm 0.07 \mathrm{~g} / \mathrm{min}, \mathrm{H}_{2} \mathrm{O}: \mathrm{C}=1.73$, and $T_{\text {reactor }}$ was kept in the range 1133 $-1168{ }^{\circ} \mathrm{C}$. For the first set of experiments $(\boldsymbol{\Delta}), \dot{m}_{\mathrm{Ar}}$ was kept constant over the tested pressure range, leading to a linear increase of $\tau$ and $p_{\mathrm{H}_{2} \mathrm{O}}$ and a reduction in $u_{\mathrm{Ar}, \mathrm{i}}$ with $p$. As expected, $X_{\mathrm{C}}$ increases with $p$ within the range $1-3$ bar due to longer $\tau$ and higher $p_{\mathrm{H}_{2} \mathrm{O}}$. For $p>3$ bar, the effect of the slower $u_{\mathrm{Ar}, \mathrm{i}}$ became predominant and $X_{\mathrm{C}}$ decreases because of insufficient particle entrainment, as verified by the presence of residual particles deposited inside the reaction 
chamber. $\eta_{\text {solar-to-fuel }}$ follows the same trend as $X_{\mathrm{C}}$. In the following two sets of experiments, $\dot{m}_{\mathrm{Ar} / \mathrm{CO}_{2}}$ was gradually increased with $p$ in order to eliminate deposition. In the second set of experiments $(\bullet), X_{\mathrm{C}}$ increases with $p$, but converges toward a constant value for $p>4$ bar because of the less favorable thermodynamics. As it can be seen, $\eta_{\text {solar-to-fuel }}$ was less dependent on $p$ due to the higher sensible heat sink of the additionally injected Ar. In the third set of experiments $(\square)$, Ar was substituted by $\mathrm{CO}_{2}$ to eliminate the use of an inert gas and study the effect on the $\mathrm{H}_{2}: \mathrm{CO}$ molar ratio. The calculation of $X_{\mathrm{C}}$, Eq. (5), was adjusted to account for the injected $\mathrm{CO}_{2}$. Also here, $X_{\mathrm{C}}$ increases with $p$ because of longer $\tau$ and higher $p_{\mathrm{H}_{2} \mathrm{O}}+p_{\mathrm{CO}_{2}}$, peaking at $94.4 \%$ for $p=4$ bar. Despite the increasing sensible heat losses, overall $\eta_{\text {solar-to-fuel }}$ improves mainly because of the higher reaction extent. The mean temperature of the metallic shell increases on average by $7.8 \mathrm{~K} / \mathrm{bar}$ and $17.3 \mathrm{~K} / \mathrm{bar}$ for $\dot{m}_{\mathrm{Ar}}$ and $\dot{m}_{\mathrm{CO}_{2}}$, respectively, because of higher effective thermal conductivity of the porous thermal insulation. The drop in $U$ when feeding $\dot{m}_{\mathrm{CO}_{2}, \mathrm{gi}}$ at $p=4$ bar is attributed to competing reactions mechanisms by $\mathrm{H}_{2} \mathrm{O}$ and $\mathrm{CO}_{2}$, including adsorption/desorption processes at active sites $[15,30]$ as the absolute amounts of $\mathrm{H}_{2}$ produced decrease with $p_{\mathrm{CO}_{2}}$ (see Table 3, Exp. 48-51), detrimentally affecting the calorific value of the syngas despite the increase in $X_{\mathrm{C}}$. For all sets of experiments $U>1.18$, peaking for the run with $\mathrm{CO}_{2}(\square)$ at 1.33 for $p=2$ bar. The molar ratios $\mathrm{H}_{2}: \mathrm{CO}$ and $\mathrm{CO}_{2}: \mathrm{CO}$ are independent of $p$ for the sets with $\dot{m}_{\mathrm{Ar}}(\boldsymbol{\Delta} \& \bullet)$. Compared with conventional autothermal gasification, the syngas quality is significantly superior and suitable for direct use in FT synthetization [31]. For the run with $\mathrm{CO}_{2}(\square), \mathrm{H}_{2}: \mathrm{CO}$ decreases and $\mathrm{CO}_{2}: \mathrm{CO}$ increases by one order of magnitude. 
$\boldsymbol{\Delta} \quad \dot{m}_{\mathrm{Ar}}=8 \mathrm{~L}_{\mathrm{N}} / \mathrm{min}$

- $\quad \dot{m}_{\mathrm{Ar}, \mathrm{gi}}=3,6,9,12,15,15 \mathrm{~L}_{\mathrm{N}} / \min$ for $p=1,2,3,4,5,6$ bar, respectively

- $\quad \dot{m}_{\mathrm{CO}_{2, \mathrm{gi}}}=3,6,9,12 \mathrm{~L}_{\mathrm{N}} / \min$ for $p=1,2,3,4$ bar, respectively
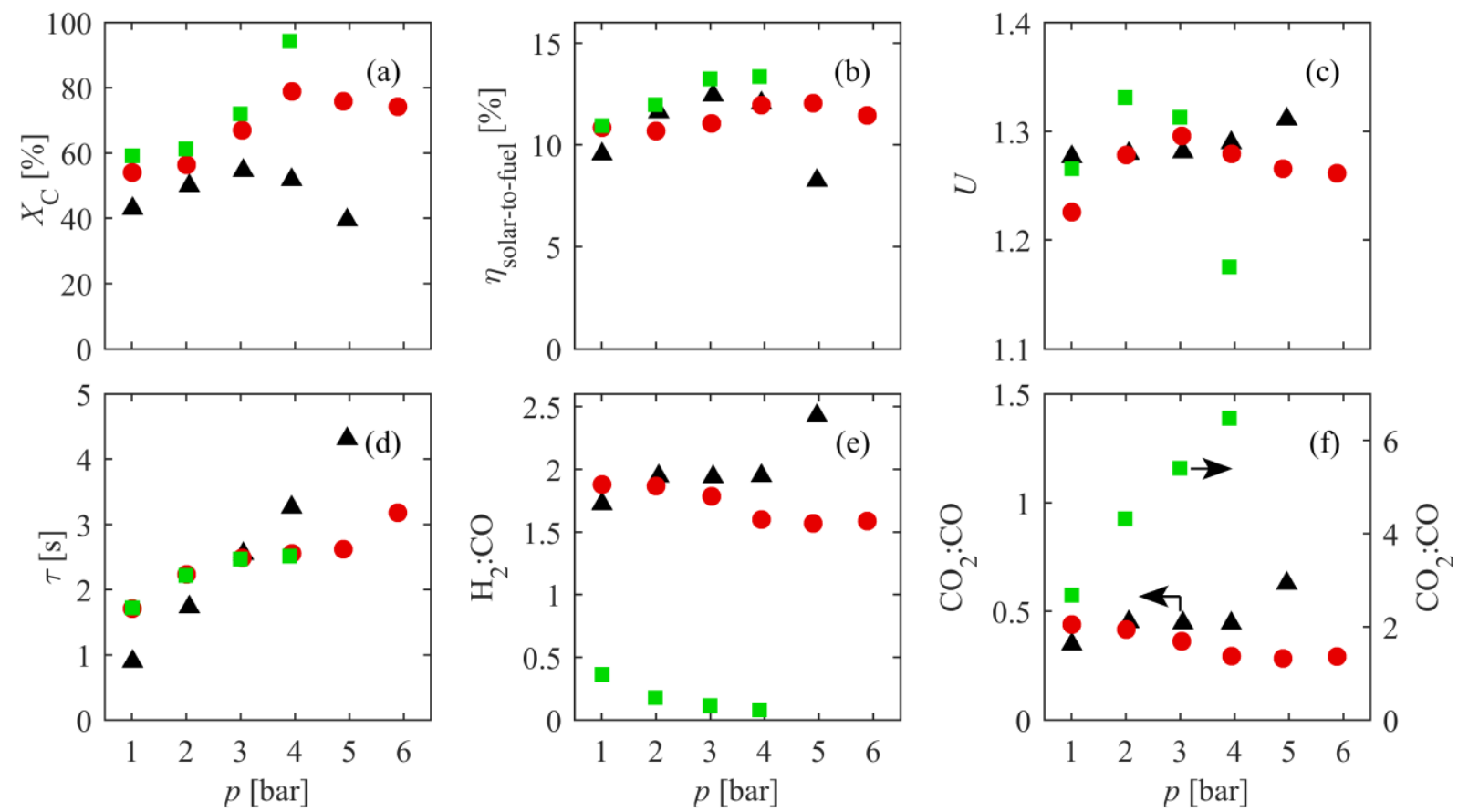

Figure 8 - a) Reaction extent, b) solar-to-fuel energy conversion efficiency, c) energetic upgrade factor, d) nominal residence time, e) $\mathrm{H}_{2}: \mathrm{CO}$ molar ratio, and f) $\mathrm{CO}_{2}: \mathrm{CO}$ molar ratio as function of $p$ obtained with the I-I solar reactor for three different vortex flow settings: $\dot{m}_{\mathrm{Ar}}$ $=8 \mathrm{~L}_{\mathrm{N}} / \min (\mathbf{\Delta}) ; \dot{m}_{\mathrm{Ar}, \mathrm{gi}}=3,6,9,12,15,15 \mathrm{~L}_{\mathrm{N}} / \mathrm{min}$ for $p=1,2,3,4,5,6$ bar, respectively $(\bullet)$; and $\dot{m}_{\mathrm{CO}_{2}, \mathrm{gi}}=3,6,9,12 \mathrm{~L}_{\mathrm{N}} / \mathrm{min}$ for $p=1,2,3,4$ bar, respectively ( $\left.\square\right)$. Additional experimental conditions: $\dot{m}_{\text {feedstock }}=0.79 \pm 0.07 \mathrm{~g} / \mathrm{min}, \mathrm{H}_{2} \mathrm{O}: \mathrm{C}=1.73$, and $T_{\text {reactor }}=1133-$ $1168^{\circ} \mathrm{C}$.

An energy balance was performed for each of the 51 experimental runs of Table 3 . Considered were: convective and radiative heat losses from the metallic shell to ambient $\dot{Q}_{\text {convection,shell }}$ and $\dot{Q}_{\text {radiation,shell, }}$ respectively, conductive heat loss to the air-cooled front

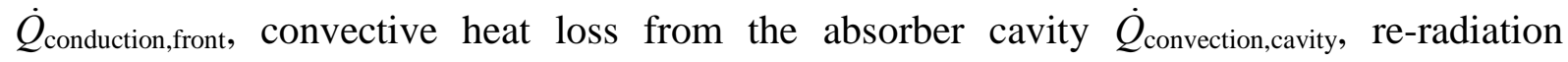
through the aperture $\dot{Q}_{\text {reradiation, }}$, reflection by the cavity $\dot{Q}_{\text {reflection, sensible heating of reactants }}$ $\dot{Q}_{\text {sensible, }}$ and heat of the reaction $\dot{Q}_{\text {chemical. }} \dot{Q}_{\text {convection,shell }}$ and $\dot{Q}_{\text {convection,cavity }}$ were calculated 


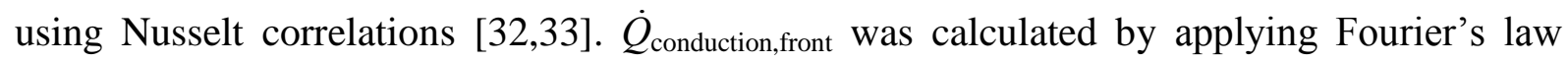
using material properties provided by the manufacturers and from literature [34]. $\dot{Q}_{\text {radiation,shell }}$ and $\dot{Q}_{\text {reradiation }}$ were calculated using the radiosity method. $\dot{Q}_{\text {reflection }}$ was computed by Monte Carlo ray-tracing. $\dot{Q}_{\text {sensible }}$ and $\dot{Q}_{\text {chemical }}$ were calculated using the enthalpy changes for the species: Ar, charcoal, $\mathrm{H}_{2} \mathrm{O}, \mathrm{H}_{2} \mathrm{CO}$, and $\mathrm{CO}_{2}$ (NIST Janaf).

On average for all 51 experimental runs of Table $3: \dot{Q}_{\text {convection,shell }}=44.8 \%$ and $\dot{Q}_{\text {radiation,shell }}=$ $8.4 \%$ of $\dot{Q}_{\text {solar }}$, which can be reduced by scaling up and improving thermal insulation. Scaling the reactor diameter by a factor of 10 could potentially double $\eta_{\text {solar-to-fuel, }}$ as the increased volume-to-surface ratio inherently reduces $\dot{Q}_{\text {convection,shell }} / \dot{Q}_{\text {solar }}$ and $\dot{Q}_{\text {radiation,shell }} / \dot{Q}_{\text {solar }}$ [35]. $\dot{Q}_{\text {conduction,front }}=12.4 \%$ of $\dot{Q}_{\text {solar }}$, which can in principle be reduced by improving the thermal insulation. $\dot{Q}_{\text {convection,cavity }}=7.8 \%$ of $\dot{Q}_{\text {solar, }}$, which is difficult to reduce and will eventually increase with forced convection [36]. $\dot{Q}_{\text {reradiation }}=13.0 \%$ of $\dot{Q}_{\text {solar }}$, which can be further reduced by incorporating a secondary concentrator [37], enabling a smaller aperture for the same radiative power input and thereby also reducing $\dot{Q}_{\text {convection,cavity. }} \dot{Q}_{\text {reflection }}=1.2 \%$ of $\dot{Q}_{\text {solar }}$, which corresponds to the apparent absorptivity of the cavity approaching a blackbody absorber. $\dot{Q}_{\text {sensible }}=9.7 \%$ of $\dot{Q}_{\text {solar }}$, which can be minimized by feeding the reactants at the stoichiometric ratio and by avoiding inert gas use, and thus eliminating heating unreacted flows. Finally, $\dot{Q}_{\text {chemical }}=2.7 \%$ of $\dot{Q}_{\text {solar }}$ (peak value of $5.1 \%$ ), which only accounts for the standard enthalpy change of Eq. (1) multiplied by $X_{\mathrm{C}}$.

\subsection{Directly-irradiated solar reactor}

Table 4 lists the operating conditions and experimental results under approximately steadystate conditions for 30 experimental runs of the D-I solar reactor. The solar reactor was operated under the following range of parameters: $p=1$ bar, $\dot{m}_{\mathrm{Ar}}=3 \mathrm{~L}_{\mathrm{N}} / \mathrm{min}, \dot{m}_{\text {feedstock }}=0.63$ $-2.03 \mathrm{~g} / \mathrm{min}, \mathrm{H}_{2} \mathrm{O}: \mathrm{C}$ molar ratio $=3.24$, and $\dot{Q}_{\text {solar }}=2.4-3.6 \mathrm{~kW}$, which corresponds to $C=$ $1228-1816$ suns. For all runs, the reactor was operated at ambient pressure because of the 
flat quartz window (196 mm-diameter, 3 mm-thickness), which can only withstand up to 0.1 bar pressure difference. A concave window would permit operating at higher pressures $[38,39]$. The nominal residence time was in the range $1.0-2.1 \mathrm{~s}$. The peak values of the performance indicators obtained were: $X_{\mathrm{C}}=69.1 \%, \eta_{\text {solar-to-fuel }}=16.9 \%$, and $U=1.25$.

Table 4 - Operating conditions for the D-I solar reactor, with experimentally measured key parameters under approximately steady-state conditions.

\begin{tabular}{|c|c|c|c|c|c|c|c|c|c|c|}
\hline \# & $\begin{array}{l}\dot{Q}_{\text {solar }} \\
{[\mathrm{W}]}\end{array}$ & $\begin{array}{l}\dot{m}_{\text {feedstock }} \\
{[\mathrm{g} / \mathrm{min}]}\end{array}$ & $\begin{array}{l}T_{\text {reactor }} \\
{\left[{ }^{\circ} \mathrm{C}\right]}\end{array}$ & $\begin{array}{l}\dot{n}_{\mathrm{H}_{2}} \\
{[\mathrm{mmol} / \mathrm{min}]}\end{array}$ & $\begin{array}{l}\dot{n}_{\mathrm{CO}} \\
{[\mathrm{mmol} / \mathrm{min}]}\end{array}$ & $\begin{array}{l}\dot{n}_{\mathrm{CO}_{2}} \\
{[\mathrm{mmol} / \mathrm{min}]}\end{array}$ & $\begin{array}{l}\tau \\
{[\mathrm{s}]}\end{array}$ & $\begin{array}{l}X_{\mathrm{C}} \\
{[\%]}\end{array}$ & $\begin{array}{l}\eta_{\text {solar-to-fuel }} \\
{[\%]}\end{array}$ & $U$ \\
\hline 1 & 2517 & 0.63 & 1119 & 31.5 & 17.9 & 7.1 & 2.1 & 52.4 & 7.9 & 1.23 \\
\hline 2 & 2499 & 0.91 & 1112 & 33.6 & 20.2 & 7.2 & 1.8 & 40.2 & 8.8 & 1.21 \\
\hline 3 & 2499 & 1.26 & 1104 & 39.6 & 27.1 & 7.2 & 1.5 & 36.1 & 10.7 & 1.21 \\
\hline 4 & 2520 & 1.57 & 1099 & 38.5 & 28.1 & 5.9 & 1.4 & 28.8 & 10.5 & 1.24 \\
\hline 5 & 2752 & 0.63 & 1162 & 38.1 & 19.4 & 9.4 & 2.1 & 60.7 & 8.4 & 1.24 \\
\hline 6 & 2760 & 0.85 & 1124 & 39.1 & 22.5 & 8.7 & 1.9 & 48.9 & 9.2 & 1.22 \\
\hline 7 & 2422 & 1.25 & 1094 & 31.7 & 22.0 & 5.5 & 1.6 & 29.2 & 9.2 & 1.26 \\
\hline 8 & 2412 & 1.51 & 1087 & 38.5 & 28.7 & 5.9 & 1.4 & 30.5 & 11.1 & 1.26 \\
\hline 9 & 2647 & 0.93 & 1133 & 59.9 & 34.6 & 13.9 & 1.7 & 69.1 & 13.9 & 1.26 \\
\hline 10 & 2639 & 0.94 & 1142 & 40.9 & 21.7 & 9.8 & 1.7 & 44.3 & 9.2 & 1.27 \\
\hline 11 & 2641 & 1.13 & 1142 & 60.3 & 36.9 & 12.4 & 1.6 & 57.8 & 14.3 & 1.27 \\
\hline 12 & 2643 & 1.12 & 1103 & 45.8 & 27.7 & 10.0 & 1.7 & 44.8 & 10.5 & 1.27 \\
\hline 13 & 2641 & 1.25 & 1129 & 57.3 & 35.5 & 11.9 & 1.5 & 50.9 & 13.8 & 1.26 \\
\hline 14 & 2633 & 1.55 & 1104 & 48.4 & 32.2 & 8.9 & 1.4 & 35.3 & 12.6 & 1.26 \\
\hline 15 & 2901 & 0.94 & 1180 & 60.3 & 31.0 & 15.6 & 1.7 & 65.8 & 11.7 & 1.25 \\
\hline 16 & 2890 & 1.14 & 1175 & 68.0 & 35.9 & 17.4 & 1.5 & 61.7 & 14.4 & 1.25 \\
\hline 17 & 2874 & 1.14 & 1173 & 60.2 & 31.8 & 15.5 & 1.5 & 54.7 & 12.8 & 1.24 \\
\hline 18 & 2884 & 1.34 & 1156 & 62.1 & 33.4 & 16.3 & 1.4 & 49.1 & 14.2 & 1.24 \\
\hline 19 & 2879 & 1.36 & 1145 & 55.3 & 31.8 & 12.6 & 1.4 & 43.3 & 11.5 & 1.26 \\
\hline 20 & 2864 & 1.49 & 1127 & 56.6 & 33.2 & 13.1 & 1.4 & 42.0 & 12.9 & 1.24 \\
\hline 21 & 3108 & 1.06 & 1216 & 68.5 & 29.0 & 20.4 & 1.5 & 61.7 & 11.9 & 1.25 \\
\hline 22 & 3114 & 1.35 & 1173 & 66.9 & 30.3 & 19.2 & 1.4 & 48.5 & 12.6 & 1.25 \\
\hline 23 & 3112 & 1.72 & 1150 & 86.4 & 47.4 & 20.7 & 1.2 & 52.5 & 16.4 & 1.26 \\
\hline 24 & 3121 & 2.02 & 1146 & 85.7 & 52.9 & 17.3 & 1.1 & 46.1 & 16.9 & 1.27 \\
\hline 25 & 3341 & 1.42 & 1194 & 86.4 & 43.5 & 22.7 & 1.3 & 61.5 & 15.5 & 1.25 \\
\hline 26 & 3328 & 1.65 & 1207 & 83.1 & 39.6 & 23.5 & 1.2 & 50.5 & 14.2 & 1.24 \\
\hline 27 & 3332 & 1.86 & 1176 & 84.0 & 43.0 & 21.7 & 1.1 & 46.0 & 14.6 & 1.25 \\
\hline 28 & 3345 & 2.03 & 1153 & 80.8 & 44.9 & 19.2 & 1.1 & 41.8 & 14.8 & 1.26 \\
\hline 29 & 3566 & 1.86 & 1209 & 87.5 & 41.0 & 24.3 & 1.1 & 46.4 & 13.8 & 1.25 \\
\hline 30 & 3555 & 2.03 & 1198 & 96.1 & 46.3 & 25.6 & 1.0 & 46.8 & 15.8 & \\
\hline
\end{tabular}


Figure $3 \mathrm{~b}$ presents a representative experimental run conducted with the D-I solar reactor. Plotted are the temporal variation of $\dot{m}_{\text {feedstock }}, \dot{Q}_{\text {solar }}, T_{\text {reactor }}, T_{\text {shell }}, T_{\text {offgas }}$ and the product gas evolution at ambient pressure. The period of the experiment considered to approximate steady-state conditions is indicated by the two vertical dotted lines. For this run, these conditions were: $p=1$ bar, $\dot{m}_{\text {feedstock }}=0.94 \mathrm{~g} / \mathrm{min}, \mathrm{H}_{2} \mathrm{O}: \mathrm{C}=3.24$, and $\dot{Q}_{\text {solar }}=2.9 \mathrm{~kW}$, leading to $T_{\text {reactor }}=1180{ }^{\circ} \mathrm{C}, T_{\text {shell }}=1061{ }^{\circ} \mathrm{C}, T_{\text {offgas }}=709{ }^{\circ} \mathrm{C}$, and yielding a syngas flow of $\dot{n}_{\mathrm{H}_{2}}=60.3$ $\mathrm{mmol} / \mathrm{min}, \dot{n}_{\mathrm{CO}}=31.0 \mathrm{mmol} / \mathrm{min}$, and $\dot{n}_{\mathrm{CO}_{2}}=15.6 \mathrm{mmol} / \mathrm{min}$. The performance indicators obtained were: $X_{\mathrm{C}}=65.8 \%$ within $\tau=1.7 \mathrm{~s}, \eta_{\text {solar-to-fuel }}=11.7 \%$, and $U=1.25$.

Figure 9 a-c present $\dot{n}$ for the species $\mathrm{H}_{2}(\bullet), \mathrm{CO}(\Delta)$, and $\mathrm{CO}_{2}(\bullet)$ as a function of $T_{\text {reactor }}$ for three slurry feeding rates: a) $\dot{m}_{\text {feedstock }}=0.91 \pm 0.04 \mathrm{~g} / \mathrm{min}$; b) $\dot{m}_{\text {feedstock }}=1.10 \pm 0.05 \mathrm{~g} / \mathrm{min}$; and c) $\dot{m}_{\text {feedstock }}=1.43 \pm 0.07 \mathrm{~g} / \mathrm{min}$. For all runs, $\dot{n}_{\text {syngas }}$ increases with $T_{\text {reactor. }}$ As for the quality of the syngas, Figure $9 \mathrm{~d}$ presents the molar ratios $\mathrm{H}_{2}: \mathrm{CO}$ and $\mathrm{CO}_{2}: \mathrm{CO}$ as a function of $T_{\text {reactor }}$ for all experimental runs. Both molar ratios increase linearly with $T_{\text {reactor }}$, independent from $\dot{m}_{\text {feedstock}}$, presumably because of the water-gas shift reaction at the exit of the solar reactor. $\mathrm{CH}_{4}$, when detected, never exceeded $0.38 \mathrm{mmol} / \mathrm{min}$. 


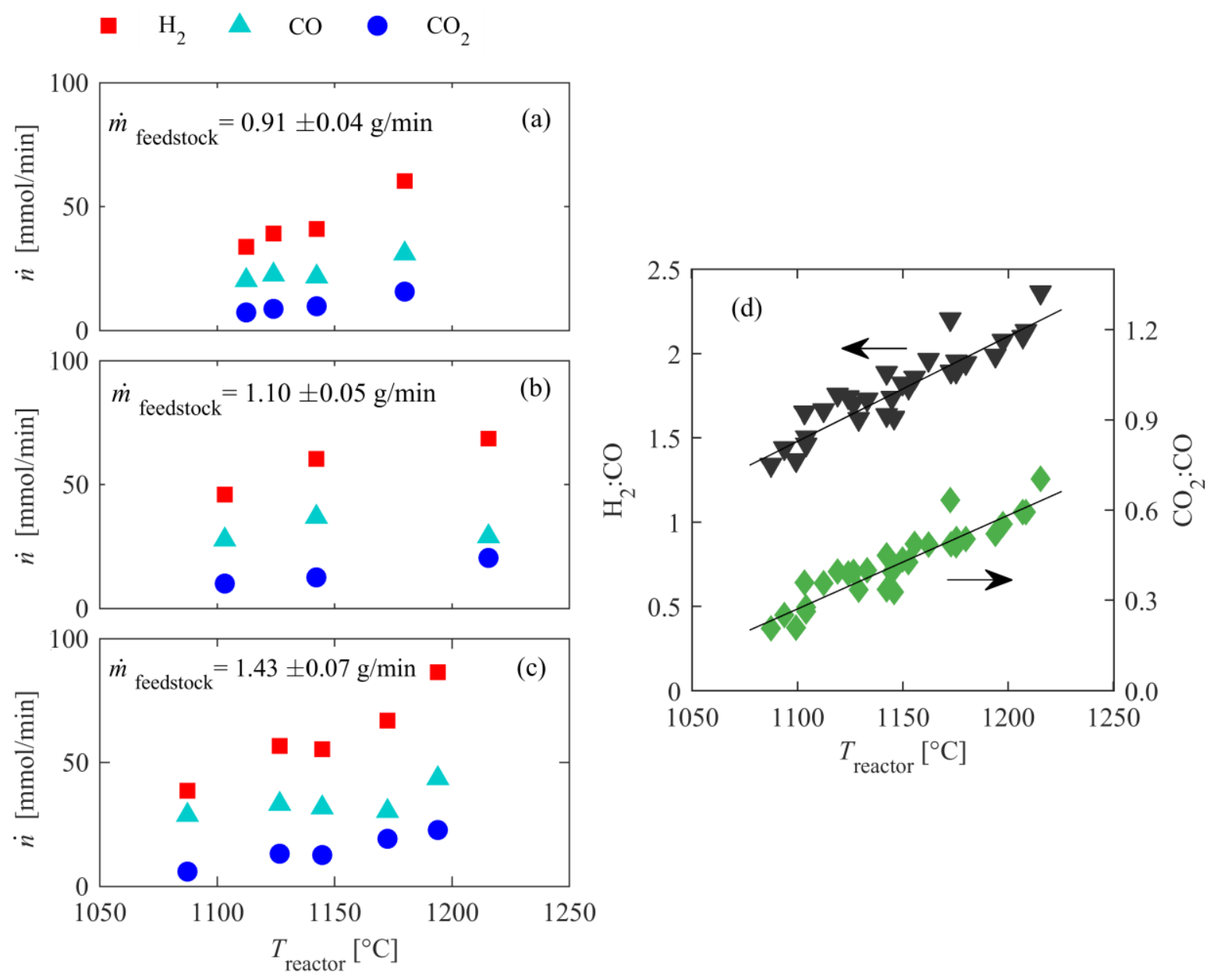

Figure 9 - a-c) Molar evolution for the species $\mathrm{H}_{2}(\square), \mathrm{CO}(\Delta)$, and $\mathrm{CO}_{2}(\bullet)$ as a function of $T_{\text {reactor }}$ for three slurry feeding rates. d) Molar ratios $\mathrm{H}_{2}: \mathrm{CO}(\boldsymbol{\nabla})$ and $\mathrm{CO}_{2}: \mathrm{CO}(\diamond)$ as function of $T_{\text {reactor}}$, obtained with the D-I solar reactor.

\subsection{Comparison of the solar reactor configurations}

Figure 10 presents $X_{\mathrm{C}}$ (a) and $\eta_{\text {solar-to-fuel }}(\mathrm{b})$ as function of $T_{\text {reactor }}$ for: the I-I solar reactor ( $\bullet$ ) operated at $p=1.0$ bar, $\dot{m}_{\mathrm{Ar}}=4 \mathrm{~L}_{\mathrm{N}} / \mathrm{min}, \dot{m}_{\text {feedstock, }}=0.82 \pm 0.02 \mathrm{~g} / \mathrm{min}$, and $\mathrm{H}_{2} \mathrm{O}: \mathrm{C}=1.73$; and the D-I solar reactor $(\square)$ operated at $p=1$ bar, $\dot{m}_{\mathrm{Ar}}=3 \mathrm{~L}_{\mathrm{N}} / \mathrm{min}, \dot{m}_{\text {feedstock }}=0.91 \pm 0.04 \mathrm{~g} / \mathrm{min}$, and $\mathrm{H}_{2} \mathrm{O}: \mathrm{C}=3.24$. Because of the significantly different heat transfer mechanisms that are inherent of the direct or indirect irradiation, different $\dot{Q}_{\text {solar }}$ and $\dot{m}_{\text {feedstock }}$ were required to reach the same $T_{\text {reactor }}$ in both solar reactor configurations. Specifically, $11 \%$ higher $\dot{m}_{\text {feedstock }}$ 
was required in the D-I solar reactor to obtain an optically thick medium for volumetric radiative absorption [20], and consequently a higher $\dot{Q}_{\text {solar }}$ was required to heat $\dot{m}_{\text {feedstock }}$ to the desired $T_{\text {reactor. }}$ Note also that $T_{\text {reactor }}$ is an average temperature measured inside the reaction chamber, but the actual particle temperature, which is pertinent for reaction rates and extents, is unknown. Thus, the comparison in terms of $X_{\mathrm{C}}$ becomes difficult because higher values were obtained for the I-I solar reactor at $T_{\text {reactor }}=1120{ }^{\circ} \mathrm{C}$ but the contrary is true at $T_{\text {reactor }}=$ $1200{ }^{\circ} \mathrm{C} . X_{\mathrm{C}}$ increases with $T_{\text {reactor }}$ for both reactors, but it is more clearly observed for the I-I configuration because of superior stability of the vortex flow. In contrast, $\eta_{\text {solar-to-fuel }}$ remains constant at around $14.3 \pm 1.1 \%$ for the I-I while varied within the range $8.8-11.7 \%$ for the DI. Furthermore, despite the less efficient heat transfer mechanism to the reaction site, the I-I solar reactor achieves higher values of $\eta_{\text {solar-to-fuel }}$ over the entire temperature range shown in Figure 10 , mainly because the required $\dot{Q}_{\text {solar }}$ to reach the desired $T_{\text {reactor }}$ was lower due to the lower $\dot{m}_{\text {feedstock }}$, lower $\mathrm{H}_{2} \mathrm{O}: \mathrm{C}$ molar ratio, and, as it will be shown in the energy analysis that follows, the lower re-radiation losses. On average, $U=1.20 \pm 0.04$ and $1.25 \pm 0.05$ for the I-I and D-I configurations, respectively, and independent of $\dot{m}_{\text {feedstock }}, \mathrm{H}_{2} \mathrm{O}: \mathrm{C}$ molar ratio, or $T_{\text {reactor. }}$ As for the syngas quality, the ranges of the $\mathrm{H}_{2}: \mathrm{CO}$ molar ratio obtained are $1.16-1.90$ and $1.34-2.36$ for the I-I and D-I configurations, respectively, mainly as a consequence of the $\mathrm{H}_{2} \mathrm{O}: \mathrm{C}$ molar ratio fed. 
I-I solar reactor

D-I solar reactor
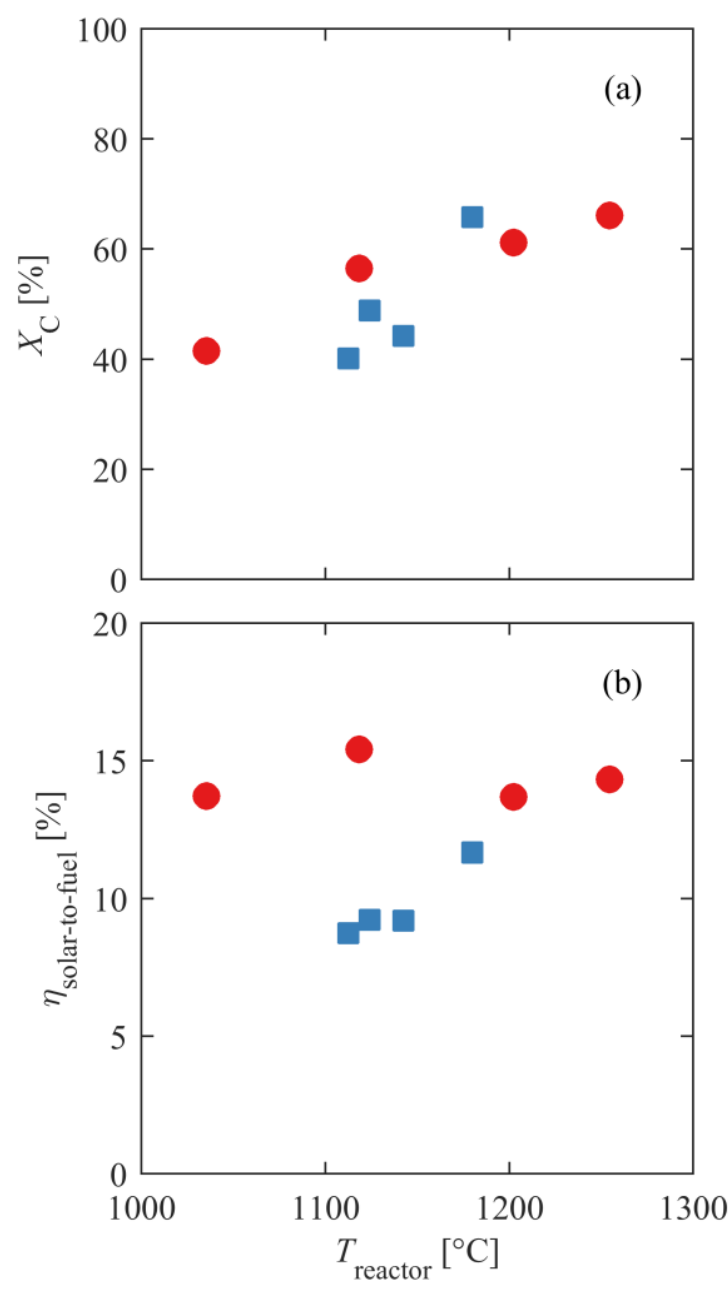

Figure 10 - a) Reaction extent, and b) solar-to-fuel energy conversion efficiency as a function of $T_{\text {reactor }}$ for the I-I ( $\bullet$ ) and D-I ( $\square$ ) solar reactors. Experimental conditions: $(\bullet) p=1$ bar, $\dot{m}_{\mathrm{Ar}}$ $=4 \mathrm{~L}_{\mathrm{N}} / \mathrm{min}, \dot{m}_{\text {feedstock }}=0.82 \pm 0.02 \mathrm{~g} / \mathrm{min}$, and $\mathrm{H}_{2} \mathrm{O}: \mathrm{C}=1.73$; and $(\square) p=1$ bar, $\dot{m}_{\mathrm{Ar}}=3$ $\mathrm{L}_{\mathrm{N}} / \mathrm{min}, \dot{m}_{\text {feedstock }}=0.91 \pm 0.04 \mathrm{~g} / \mathrm{min}$, and $\mathrm{H}_{2} \mathrm{O}: \mathrm{C}$ molar ratio $=3.24$

Figure 11 presents the energy partition for the I-I and the D-I solar reactors, given as percentage of $\dot{Q}_{\text {solar }}$ averaged over all experimental runs at ambient pressure under approximately steady-state conditions. For the D-I solar reactor, the conductive heat losses are reported as $\dot{Q}_{\text {convection,shell }}+\dot{Q}_{\text {radiation,shell }}[20] . \dot{Q}_{\text {sensible }}$ is higher for the D-I solar reactor as a result of the higher $\dot{m}_{\text {feedstock }}, \mathrm{H}_{2} \mathrm{O}: \mathrm{C}$ molar ratio, and $\dot{m}_{\mathrm{Ar}}$ needed for protecting the window. $\dot{Q}_{\text {conduction,front }}$ is significantly lower in the I-I solar reactor because the water-cooling 
refrigeration of the window's mount for the D-I solar reactor was replaced with air-cooling of the windowless front. Further, the higher apparent absorptivity of the I-I solar reactor led to lower $\dot{Q}_{\text {reradiation }}$ at the expense of the additional $\dot{Q}_{\text {convection,cavity. }} \dot{Q}_{\text {chemical }}$ is comparable, but as seen in Figure 10 and discussed in the previous paragraph, $\eta_{\text {solar-to-fuel }}$ is higher for the I-I configuration over the temperature range $1000-1300{ }^{\circ} \mathrm{C}$.

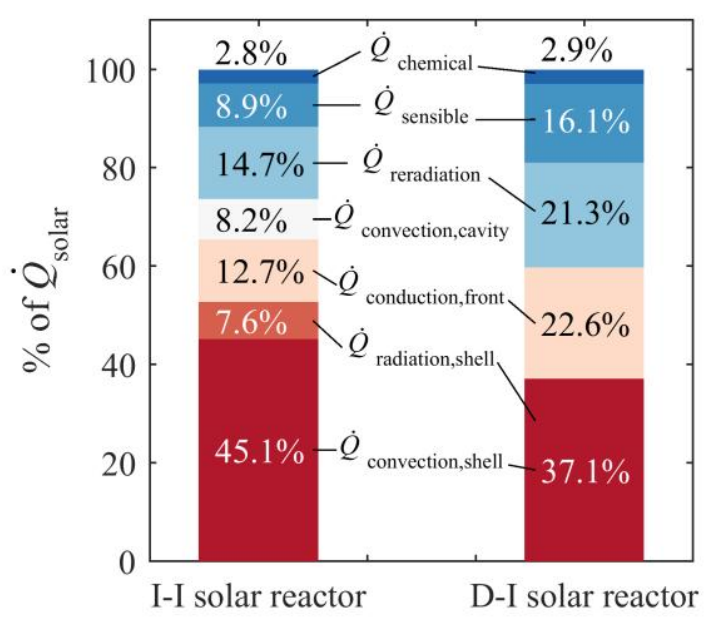

Figure 11 - Energy partition for the I-I and D-I solar reactors, given as percentage of the solar radiative power input averaged for all experimental runs at ambient pressure and under approximate steady-state conditions.

\section{Summary \& Conclusions}

We experimentally demonstrated for the first time the solar-driven gasification of carbonaceous feedstock at high pressures using a robust design of an indirectly-irradiated solar thermochemical reactor. A peak solar-to-fuel energy conversion efficiency of $20 \%$ and almost complete conversion in less than 5 seconds point out to the technical feasibility of the solar reactor technology. For all 51 solar runs, the calorific value of the feedstock was upgraded in the range $16-35 \%$, underpinning the benefit of solar-upgrading, in contrast to 
the inherent downgrading that results from autothermal gasification. High-quality pressurized syngas with no tars was produced, facilitating its integration to gas-to-liquid processing. Ar was substituted by $\mathrm{CO}_{2}$, increasing the partial pressure of the gasifying agent and eliminating the consumption of expensive inert gas. Higher reaction extents and comparable solar-to-fuel energy conversion efficiencies and calorific upgrade factors were obtained on average with the indirectly-irradiated solar reactor than with the directly-irradiated solar reactor.

\section{Nomenclature}

Latin symbols

C solar concentration ratio $\left[\mathrm{kW} / \mathrm{m}^{2}\right]$

$d \quad$ particle size $[\mu \mathrm{m}]$

$L H V \quad$ lower heating value $[\mathrm{MJ} / \mathrm{kg}]$

$\dot{m} \quad$ mass flow rate $[\mathrm{g} / \mathrm{min}],\left[\mathrm{L}_{\mathrm{N}} / \mathrm{min}\right]$

$\dot{n} \quad$ molar flow rate $[\mathrm{mmol} / \mathrm{min}]$

$p \quad$ pressure $[\mathrm{bar}]$

$\dot{Q} \quad$ power $[\mathrm{W}]$

$R \quad$ universal gas constant: $8.314 \mathrm{~J} /(\mathrm{K} \mathrm{mol})$

$r \quad$ radial coordinate [mm]

$T$ temperature $\left[{ }^{\circ} \mathrm{C}\right],[\mathrm{K}]$

$t \quad$ time [min]

$U \quad$ energetic upgrade factor

$u \quad$ gas velocity $[\mathrm{m} / \mathrm{s}]$

$V \quad$ volume $\left[\mathrm{m}^{3}\right]$

$X_{\mathrm{C}} \quad$ reaction extent [\%]

$x \quad$ H:C molar ratio 


$$
\begin{array}{ll}
y & \mathrm{O}: \mathrm{C} \text { molar ratio } \\
z & \text { horizontal coordinate }[\mathrm{mm}]
\end{array}
$$

Greek symbols

$$
\begin{array}{ll}
\eta_{\text {solar-to-fuel }} & \text { solar-to-fuel energy conversion efficiency [\%] } \\
\tau & \text { nominal residence time }[\mathrm{s}] \\
\varphi & \text { angular coordinate }\left[{ }^{\circ}\right]
\end{array}
$$

Subscripts

\begin{tabular}{ll} 
cavity & cavity \\
chemical & chemical \\
conduction & heat conduction \\
convection & free convection \\
feedstock & feedstock, charcoal \\
gi & gradually increasing \\
i & inlet \\
N & normal conditions: 273.15 K and $1 \mathrm{~atm}$ \\
offgas & off gas stream \\
radiation & radiation \\
reactor & reactor \\
reflection & reflection \\
reradiation & re-radiation \\
sensible & sensible heat \\
shell & metallic shell \\
solar-to-fuel & solar-to-fuel \\
\hline
\end{tabular}


syngas

v10,50,90 syngas

upper threshold particle size in $\mu \mathrm{m}$

\begin{tabular}{ll}
\multicolumn{2}{l}{ Abbreviations } \\
CCD & charged coupled device \\
D-I & directly-irradiated \\
FT & Fischer-Tropsch \\
IR & infrared \\
GC & gas chromatograph \\
HFSS & high-flux solar simulator \\
I-I & indirectly-irradiated
\end{tabular}

\section{Acknowledgements}

We gratefully acknowledge the financial support by the Swiss National Science Foundation (Grant Nr. IZLIZ2_156474), the European Union under the 7th Framework Program (STAGE-STE, Grant Nr. 609837), and the Australian Renewable Energy Agency (Grants 2F-013). We thank G. Maag, D. Hermann, and D. Wuillemin for their technical support.

\section{References}

[1] Piatkowski N, Wieckert C, Weimer AW, Steinfeld A. Solar-driven gasification of carbonaceous feedstock-a review. Energy Environ Sci 2011;4:73-82. doi:10.1039/C0EE00312C.

[2] Kaniyal AA, Eyk PJ Van, Nathan GJ, Ashman PJ, Pincus JJ. Polygeneration of Liquid 
Fuels and Electricity by the Atmospheric Pressure Hybrid Solar Gasi fi cation of Coal. Energy \& Fuels 2013;27:3538-55. doi:10.1021/ef400198v.

[3] Guo P, Van Eyk PJ, Saw WL, Ashman PJ, Nathan GJ, Stechel EB. Performance assessment of Fischer-Tropsch liquid fuels production by solar hybridized dual fluidized bed gasification of lignite. Energy and Fuels 2015;29:2738-51. doi:10.1021/acs.energyfuels.5b00007.

[4] Muroyama A, Shinn T, Fales RC, Loutzenhiser PG. Modeling of a DynamicallyControlled Hybrid Solar/Autothermal Steam Gasification Reactor. Energy \& Fuels 2014;28:140908004405007. doi:10.1021/ef501535r.

[5] Hathaway BJ, Kittelson DB, Davidson JH. Integration of Solar Gasification With Conventional Fuel Production: The Roles of Storage and Hybridization. J Sol Energy Eng 2013;136:11024. doi:10.1115/1.4025971.

[6] Gregg DW, Aiman WR, Otsuki HH, Thorsness CB. Solar coal gasification. Sol Energy 1980;24:313-21. doi:10.1016/0038-092X(80)90489-2.

[7] De Filippis P, Borgianni C, Paolucci M, Pochetti F. Prediction of syngas quality for two-stage gasification of selected waste feedstocks. Waste Manag 2004;24:633-9. doi:10.1016/j.wasman.2004.02.014.

[8] Wu Y, Yang W, Blasiak W. Energy and exergy analysis of high temperature agent gasification of biomass. Energies 2014;7:2107-22. doi:10.3390/en7042107.

[9] Gregg DW, Taylor RW, Campbell JH, Taylor JR, Cotton A. Solar gasification of coal, activated carbon, coke and coal and biomass mixtures. Sol Energy 1980;25:353-64. doi:10.1016/0038-092X(80)90347-3.

[10] Piatkowski N, Wieckert C, Steinfeld A. Experimental investigation of a packed-bed 
solar reactor for the steam-gasification of carbonaceous feedstocks. Fuel Process Technol 2009;90:360-6. doi:10.1016/j.fuproc.2008.10.007.

[11] Wieckert C, Obrist A, von Zedtwitz P, Maag G, Steinfeld A. Syngas Production by Thermochemical Gasification of Carbonaceous Waste Materials in a $150 \mathrm{~kW}$ th Packed-Bed Solar Reactor. Energy \& Fuels 2013;27:47770-4776. doi:10.1021/ef4008399.

[12] Flechsenhar M, Sasse C. Solar gasification of biomass using oil shale and coal as candidate materials. Energy 1995;20:803-10. doi:10.1016/0360-5442(95)00023-A.

[13] Taylor RW, Berjoan R, Coutures JP. Solar gasification of carbonaceous materials. Sol Energy 1983;30:513-25. doi:10.1016/0038-092X(83)90063-4.

[14] Murray JP, Fletcher EA. Reaction of steam with cellulose in a fluidized bed using concentrated sunlight. Energy 1994;19:1083-98. doi:10.1016/0360-5442(94)90097-3.

[15] Müller R, von Zedtwitz P, Wokaun A, Steinfeld A. Kinetic investigation on steam gasification of charcoal under direct high-flux irradiation. Chem Eng Sci 2003;58:5111-9. doi:10.1016/j.ces.2003.08.018.

[16] Kodama T, Gokon N, Enomoto S, Itoh S, Hatamachi T. Coal Coke Gasification in a Windowed Solar Chemical Reactor for Beam-Down Optics. J Sol Energy Eng 2010;132:41004. doi:10.1115/1.4002081.

[17] Gokon N, Izawa T, Kodama T. Steam gasification of coal cokes by internally circulating fluidized-bed reactor by concentrated Xe-light radiation for solar syngas production. Energy 2015;79:264-72. doi:10.1016/j.energy.2014.11.012.

[18] Lichty P, Perkins C, Woodruff B, Bingham C, Weimer A. Rapid High Temperature Solar Thermal Biomass Gasification in a Prototype Cavity Reactor. J Sol Energy Eng 
2010;132:11012. doi:10.1115/1.4000356.

[19] Kruesi M, Jovanovic ZR, Steinfeld A. A two-zone solar-driven gasifier concept: Reactor design and experimental evaluation with bagasse particles. Fuel 2014;117:680-7. doi:10.1016/j.fuel.2013.09.011.

[20] Z'Graggen A, Haueter P, Trommer D, Romero M, de Jesus JC, Steinfeld A. Hydrogen production by steam-gasification of petroleum coke using concentrated solar power-II Reactor design, testing, and modeling. Int J Hydrogen Energy 2006;31:797-811. doi:10.1016/j.ijhydene.2005.06.011.

[21] Melchior T, Perkins C, Lichty P, Weimer AW, Steinfeld A. Solar-driven biochar gasification in a particle-flow reactor. Chem Eng Process Process Intensif 2009;48:1279-87. doi:10.1016/j.cep.2009.05.006.

[22] Denk T, Haueter P, Vidal A, Valverde A. Upscaling of a Solar Powered Reactor for Co2-Free Syngas and Hydrogen Production. System 2010:1-8. doi:10.13140/2.1.2294.2080.

[23] Poživil P, Ettlin N, Stucker F, Steinfeld A. Modular Design and Experimental Testing of a $50 \mathrm{kWth}$ Pressurized-Air Solar Receiver for Gas Turbines. J Sol Energy Eng 2015;137:31002. doi:10.1115/1.4028918.

[24] Demirbas A, Gullu D, Çaglar A, Akdeniz F. Estimation of Calorific Values of Fuels from Lignocellulosics. Energy Sources 1997;19:765-70. doi:10.1080/00908319708908888.

[25] Petrasch J, Coray P, Meier A, Brack M, Häberling P, Wuillemin D, et al. A Novel 50 kW 11,000 suns High-Flux Solar Simulator Based on an Array of Xenon Arc Lamps. J Sol Energy Eng 2007;129:405. doi:10.1115/1.2769701. 
[26] Kragten J. Calculating Standard Deviations and Confidnce Intervals with a Univerally Applicable Spreadsheet Technique. Analyst 1994;11:2161-5. doi:10.1039/AN9941902161.

[27] Porada S. The reactions of formation of selected gas products during coal pyrolysis 2004;83:1191-6. doi:10.1016/j.fuel.2003.11.007.

[28] Zedtwitz P v., Steinfeld A. The solar thermal gasification of coal - Energy conversion efficiency and CO2 mitigation potential. Energy 2003. doi:10.1016/S03605442(02)00139-1.

[29] Chinnici A, Arjomandi M, Tian ZF, Lu Z, Nathan GJ. A Novel Solar ExpandingVortex Particle Reactor: Influence of Vortex Structure on Particle Residence Times and Trajectories. Sol Energy 2015;122:58-75. doi:10.1016/j.solener.2015.08.017.

[30] Guizani C, Jeguirim M, Gadiou R, Escudero Sanz FJ, Salvador S. Biomass char gasification by $\mathrm{H} 2 \mathrm{O}, \mathrm{CO} 2$ and their mixture: Evolution of chemical, textural and structural properties of the chars. Energy 2016;112:133-45. doi:10.1016/j.energy.2016.06.065.

[31] Wender I. Reactions of synthesis gas. Fuel Process Technol 1996;48:189-297. doi:10.1016/S0378-3820(96)01048-X.

[32] Incropera F, DeWitt DP. Fundamentals of Heat and Mass Transfer. 1981.

[33] Wu SY, Xiao L, Cao Y, Li YR. Convection heat loss from cavity receiver in parabolic dish solar thermal power system: A review. Sol Energy 2010;84:1342-55. doi:10.1016/j.solener.2010.04.008.

[34] Munro RG. Material Properties of a Sintered $\alpha$-SiC. J Phys Chem Ref Data 1997;26:1195-201. doi:10.1063/1.556000. 
[35] Z'Graggen A, Steinfeld A. Hydrogen production by steam-gasification of carbonaceous materials using concentrated solar energy - V. Reactor modeling, optimization, and scale-up. Int J Hydrogen Energy 2008;33:5484-92.

doi:10.1016/j.ijhydene.2008.07.047.

[36] Flesch R, Stadler H, Uhlig R, Hoffschmidt B. On the in fl uence of wind on cavity receivers for solar power towers : An experimental analysis. Appl Therm Eng 2015;87:724-35. doi:10.1016/j.applthermaleng.2015.05.059.

[37] R. Winston and W. T. Welford. Design of nonimaging concentrators as second stages in tandem with image-forming first-stage concentrators. Appl Opt 1980;19:347-51. doi:10.1364/AO.19.000347.

[38] Karni J, Kribus a., Ostraich B, Kochavi E. A High-Pressure Window for Volumetric Solar Receivers. J Sol Energy Eng 1998;120:101. doi:10.1115/1.2888051.

[39] Röger M, Pfänder M, Buck R. Multiple Air-Jet Window Cooling for High-Temperature Pressurized Volumetric Receivers: Testing, Evaluation, and Modeling. J Sol Energy Eng 2006;128:265. doi:10.1115/1.2212437. 